\title{
On-the-Job Search and Precautionary Savings: Theory and Empirics of Earnings and Wealth Inequality*
}

\author{
Jeremy Lise ${ }^{\dagger}$ \\ Queen's University
}

Version of January 13, 2006

\begin{abstract}
In this paper, I develop and estimate a model of the labor market that can account for both the inequality in earnings and the much larger inequality in wealth observed in the data. I show that an equilibrium model of on-the-job search, augmented to account for saving decisions of workers, provides a direct and intuitive link between the empirical earnings and wealth distributions.

The mechanism that generates the high degree of wealth inequality in the model is the dynamic of the "wage ladder" resulting from the search process. There is an important asymmetry between the incremental wage increases generated by on-the-job search (climbing the ladder) and the drop in income associated with job loss (falling off the ladder). The behavior of workers in low paying jobs is primarily governed by the expectation of wage growth, while the behavior of workers near the top of the distribution is driven by the possibility of job loss. This feature of the model generates differential savings behavior at different points in the earnings distribution. The wage growth expected by low wage workers, combined with the fact that their earnings are not much higher than unemployment benefits, causes them to dis-save. As a worker's wage increases, the incentive to save increases: the potential for wage growth declines and it becomes increasingly important to insure against the large income reduction associated with job loss. The fact that high wage and low wage workers have such different savings behavior generates an equilibrium wealth distribution that is much more unequal than the equilibrium wage distribution. I estimate the structural parameters of the model by simulation-based methods using the 1979 youth cohort of the NLSY. The estimates indicate that the micro-level search and savings behavior-estimated from the dynamics of individuals' labor market histories and wealth accumulation decisions-aggregates to replicate the cross-sectional inequality in earnings and wealth for this cohort.
\end{abstract}

${ }^{*}$ I am grateful for the advice and support of Shannon Seitz and Allen Head. I have also benefited from discussions with Tom Crossley, Chris Ferrall, Jean-François Houde, Susumu Imai, Kenneth Judd, James MacKinnon, Krishna Pendakur, Katsumi Shimotsu, Randy Wright, seminar participants at Queen's University, Simon Fraser University, and the 2005 Chicago-Argonne Institute on Computational Economics. Financial support from the Social Sciences and Humanities Research Council of Canada (SSHRC) is appreciated.

†Phone: (613) 533-2292, E-mail: lisej@econ.queensu.ca, Web: http://www.econ.queensu.ca/students/lise 


\section{Introduction}

In this paper I provide a framework that accounts for both employment transitions and savings behavior at the micro-level and the joint distribution of wealth and earnings at the aggregate level. I do so by developing and estimating an equilibrium search model with saving, where the joint distribution of wealth and earnings is the equilibrium outcome from a labor market characterized by informational frictions and the possibility of job destruction.

Labor markets are characterized by a surprisingly large degree of wage dispersion across workers, even within narrowly defined markets. This leads to earnings inequality which is large, and exists even within groups of observationally similar individuals. Accompanying the large dispersion in wages is an even larger dispersion in wealth. In industrialized countries, wealth is much more unequal than earnings. The distribution of wealth is characterized by a long right tail; a very large amount of wealth is held by a small fraction of individuals. Many households, and in some countries the majority of households, never accumulate much private wealth. The primary challenge for any theory of wealth inequality is to simultaneously produce the low median wealth and the very long right tail. ${ }^{1}$

Although wealth dispersion is not usually considered a labor market feature, it is the cumulative result of decisions made by individuals who live in an environment characterized by lots of wage dispersion and lots of job turnover, both in terms of transitions between employment and unemployment, and also in terms of transitions between jobs. There are numerous theories for why earnings are so unequal, all relying on ex ante productivity differences across workers. ${ }^{2}$ Mortensen (1990) and Burdett and Mortensen (1998) provide an alternative model of earnings dispersion, primarily aimed at addressing the question "Why are similar workers paid differently?" This framework focuses on differences in firm productivity and recruiting or wage policies combined with informational frictions that make it costly for workers to become fully informed about the wage policies of all firms. This framework, generally referred to as the Burdett-Mortensen model, is attractive because it provides a unified theory of job turnover and earnings inequality, even when workers are ex ante identical. ${ }^{3}$ Search models of the labor market provide a rigorous

\footnotetext{
${ }^{1}$ The empirical regularities of income inequality have been documented by Gottschalk and Smeeding (1997) for OECD countries and by Budría Rodríguez, Díaz-Giménez, Quadrini, and Ríos-Rull (2002) for the United States. Davies and Shorrocks (2000) outline the stylized facts for wealth inequality.

${ }^{2}$ See Neal and Rosen (2000) for an overview.

${ }^{3}$ Mortensen (2003) provides a complete development of the Burdett-Mortensen model, including many extensions
} 
yet tractable framework for addressing questions of the dynamics associated with labor market experiences, including individual workers' wage dynamics and wage dispersion. ${ }^{4}$ In this paper I demonstrate that search models are also well suited to analyzing workers' (precautionary) savings behavior and the resulting wealth inequality.

The mechanism that generates the high degree of wealth inequality in the model is the dynamic of the "wage ladder" resulting from the search process. There is an important asymmetry between the incremental wage increases generated by on-the-job search (climbing the ladder) and the drop in income associated with job loss (falling off the ladder). The behavior of workers in low paying jobs is primarily governed by the expectation of wage growth, while the behavior of workers near the top of the distribution is driven by the possibility of job loss. This feature of the model generates differential savings behavior at different points in the earnings distribution. The wage growth expected by low wage workers, combined with the fact that their earnings are not much higher than unemployment benefits, causes them to dis-save. As a worker's wage increases, the incentive to save increases: the potential for wage growth declines and it becomes increasingly important to insure against the large income reduction associated with job loss. The fact that high wage and low wage workers have such different savings behavior generates an equilibrium wealth distribution that is much more unequal than the equilibrium wage distribution.

I estimate the structural parameters of the model by simulation-based methods using the 1979 youth cohort of the National Longitudinal Survey of Labor Market Experience (NLSY79). This data is particularly well suited for my purposes as it contains weekly observations on the labor market status and wages of individuals from 1978 through 2002. From 1985 onward, with the exception of 1991, observations on assets are recorded at each interview date. I use simulationbased estimation to deal with the fact that wealth, which is a state variable, is only observed at irregularly spaced interview dates, and that unemployment and job durations rarely coincide exactly with these observations. Sampling data from the simulated model at the same frequency that the actual data was collected addresses this problem. Given estimates for the model from the micro observations on individual labor market histories and asset levels, I compare the distributions of earnings and wealth implied by the model with the those in the data. The wealth distribution which make the framework well suited to empirical analysis of labor markets.

${ }^{4}$ A recent survey of search theory is provided by Rogerson, Shimer, and Wright (2005). A survey of the empirical search literature is provided by Eckstein and van den Berg (2003). 
implied by the model matches the data almost exactly.

This paper contributes to the recent literature that attempts to account for wealth inequality, such as Krusell and Smith (1998) and Castañeda, Díaz-Giménez, and Ríos-Rull (2003). Both of these papers study wealth inequality within a framework of ex ante identical individuals who behave optimally in the face of uninsurable idiosyncratic shocks to income. They find that it is difficult to jointly reconcile the individual income dynamics with aggregate income and wealth inequality. Krusell and Smith find that the fit to wealth inequality can be improved dramatically if heterogeneity in the rate of time preference is used. Small differences in the rate of time preference across individuals results in large differences in savings behavior. Castañeda, Díaz-Giménez, and Ríos-Rull adopt an alternative approach. Instead of using an income process estimated from the data, they target the Lorenz coordinates for income and wealth inequality, and let the income dynamics be whatever is necessary to generate the observed inequality. As a result, the model can replicate the income and wealth distributions found in the data, but the dynamics of the model's income process do not have a direct empirical counterpart. Here, I adopt a different approach. I estimate the dynamics of the income process within an equilibrium labor search model, and aggregate up earnings and wealth to check whether the inequality in earnings and wealth from the model replicates that observed in the data. This exercise requires the model to fit both the dynamics of individual labor market histories and the cross-sectional implications for the distribution of earnings and assets. The model is successful on both fronts.

This paper is also related to the literature on search models that include a savings decision. ${ }^{5}$ This literature has been primarily concerned with the effect of an individual's wealth level on his search effort or reservation wage decision. My contribution is to fully develop a theory for optimal savings in this environment, and to show that the parameters characterizing the frictions in the labor market have a direct and intuitive interpretation in the workers' optimal savings decision, and imply that wealth will be much more unequal than earnings.

The remainder of the article is organized as follows. Section 2 presents the economic environment and develops the optimal search and savings decisions of workers. This section also explores

\footnotetext{
${ }^{5}$ This literature included the original theoretical contribution on risk aversion and reservations wages by Danforth (1979), and the recent contributions of Acemoglu and Shimer (1999), Costain (1999), Browning, Crossley, and Smith (2003), Lentz (2005), Lentz and Tranæs (2005), and Rendón (2006). Direct empirical support for a positive correlation between wealth levels and unemployment durations is provided by Bloemen and Stancanelli (2001), Alexopoulos and Gladden (2002), and Algan, Chéron, Hairault, and Langot (2003).
} 
the mechanism relating labor market frictions to the joint distribution of wages and assets. Section 4 details techniques used to numerically solve the model. Section 5 describes the data and subsample used for the estimation, and presents a descriptive look at the data, highlighting the correlations that relate to important implications of the model. Estimation issues and a strategy for identification of the model parameters using simulation based estimation methods are presented in Section 6. Estimation results, and the quantitative implications of the model, are presented in Section 7. Section 8 concludes and provides directions for further research. All proofs and extended derivations are provided in the Appendix.

\section{The Economy}

In this section, I present an equilibrium search model in the spirit of Burdett (1978), Burdett and Mortensen (1998), and Christensen, Lentz, Mortensen, Neumann, and Werwatz (2005). The model is extended to include risk-averse workers who face incomplete markets and the inability to fully insure consumption streams. The introduction of assets induces an endogenous distribution of search intensity that is a function of the joint distribution of wages and assets. The firm side of the problem and the equilibrium conditions remain largely intact from Burdett and Mortensen, where firms are characterized by continuous heterogeneity in productivity as developed in Bontemps, Robin, and van den Berg (2000) and summarized in Mortensen (2003).

\subsection{The Environment}

Time is continuous and there is no aggregate uncertainty. Within a well-defined labor market, workers are homogeneous in terms of productivity. Workers are ex ante identical, but will differ ex post due to differing labor market histories. Firms are assumed to differ ex ante by productivity. ${ }^{6}$ A labor market is characterized by a continuum of workers with unit mass. Workers are risk averse and derive utility from consumption and disutility from the effort of searching for a new job. It is assumed that workers know the stationary wage offer distribution but cannot observe the wage policy of all firms; they only observe the wage offer of the firm they contact. Unemployed workers contact firms randomly at a rate that is increasing in search effort. Employed workers contact firms

\footnotetext{
${ }^{6}$ Firm heterogeneity is an essential component for obtaining an equilibrium wage distribution with the characteristics of an empirical wage distribution.
} 
in the same way. Additionally, they face a constant and exogenous probability that their job will terminate and they will transit to unemployment. Markets are incomplete in the sense that workers cannot trade a complete set of contingent claims for consumption. Workers can only self-insure against income loss by accumulating assets. I assume that firms pursue a stationary wage policy. The wage initially offered to a worker remains in effect as long as the worker and firm remain matched. I also assume that firms do not make counteroffers when their workers receive a higher offer. $^{7}$

\subsection{The Workers' Problem}

Let the workers' planning horizon be infinite and let consumption and search effort streams be ordered according to

$$
\mathrm{E}_{0} \int_{0}^{\infty} \mathrm{e}^{-\rho t}\left[u\left(c_{t}\right)-e\left(s_{t}\right)\right] d t
$$

where $\rho$ is the subjective rate of time preference, $c_{t}$ is the instantaneous consumption flow at time $t$, and $s_{t}$ is the search effort at time $t .{ }^{8}$ Utility from consumption is increasing and concave, with boundary condition $\lim _{c \rightarrow \zeta} u^{\prime}(c)[c-\zeta]=\infty$, for some minimum necessary consumption level $\zeta \geq 0$. Disutility from search is increasing and strictly convex, with boundary condition $e(0)=$ $e^{\prime}(0)=0$. At any time $t$ the worker may be unemployed or employed. Workers search for jobs and make consumption decisions both when unemployed and when employed. The probability of finding a job is described by a Poisson arrival process, where the arrival rate depends on the amount of search effort of the worker: $\lambda s .{ }^{9}$ The workers face a known wage offer distribution $F(w)$, which is determined in equilibrium. Additionally, when employed, jobs are exogenously destroyed at exponential rate $\delta . W(a, w)$ denotes the expected present value of being employed with assets $a$ and a wage $w$, and $U(a)$ denotes the expected present value of being unemployed with asset level $a$.

The budget constraint can be described by the asset accumulation equation and the stochastic process governing labor income. A worker's assets accumulate according to

$$
d a=[r a+i-c] d t \quad \text { subject to } \quad a \geq \underline{a},
$$

\footnotetext{
${ }^{7}$ Coles (2001) shows that concern for reputation can sustain this wage policy.

${ }^{8}$ All notation is collected in Appendix E.

${ }^{9}$ There is no loss of generality in assuming search effort affects the arrival rate multiplicatively. All the results in the paper go through with the more general function $\lambda(s)$ as long as $\lambda^{\prime}(s)>0$ and $\lambda^{\prime \prime}(s) \leq 0$.
} 
where $r$ is the risk free interest rate, $a$ is the current asset level, $i$ is income from wages or unemployment benefits, $c$ is consumption, and $\underline{a}$ is the lower bound on assets. A worker's wage or benefit income changes stochastically according to

$$
d i= \begin{cases}d q_{\lambda s} 1(W(a, x) \geq U(a))[x-b], & \text { when unemployed } \\ d q_{\lambda s} 1(W(a, x) \geq W(a, w))[x-w]+[b-w] d q_{\delta}, & \text { when employed }\end{cases}
$$

where $1(\cdot)$ is the indicator function that takes a value of one when the argument is true and zero otherwise, $x$ is drawn from the wage offer distribution $F(w), d q_{\lambda s}=1$ when a job offer arrives and 0 otherwise, and $d q_{\delta}=1$ when a job is exogenously destroyed and 0 otherwise. ${ }^{10}$

Consider the problem of a worker who is currently unemployed with assets $a$. At each instant the worker faces the possibility, that is increasing in search effort $s$, of a job offer with Poisson probability $\lambda s$. When an offer arrives, he will accept it if the value of working at the offered wage $W(a, w)$ exceeds the value of remaining unemployed $U(a)$. Since both the time until a job offer arrives and the potential wage once an offer is received are uncertain, the problem facing the unemployed worker is to decide how much to consume at each instant while unemployed, how hard to search for work, and the minimum acceptable wage offer, $R(a)$, that will induce a move from unemployment to employment. In general all of these decisions will depend on current assets $a$. When employed, workers engage in on-the-job search, and face an exogenous probability $\delta$ of job destruction.

The problem outlined in equations (1), (2), and (3) can be conveniently represented using the continuous time Bellman equations for the value of being unemployed with assets $a$ and the value of being employed with assets $a$ and wage $w):^{11}$

$$
\begin{aligned}
& \rho U(a)=\max _{0 \leq c \leq a-\underline{a}, 0 \leq s}\{\left\{(c)-e(s)+U_{a}(a)[r a+b-c]\right. \\
&\left.+\lambda s \int \max \{W(a, x)-U(a), 0\} d F(x)\right\} \\
& \rho W(a, w)=\max _{0 \leq c \leq a-\underline{a}, 0 \leq s}\left\{u(c)-e(s)+W_{a}(a, w)[r a+w-c]\right. \\
&\left.+\lambda s \int \max \{W(a, x)-W(a, w), 0\} d F(x)+\delta[U(a)-W(a, w)]\right\} .
\end{aligned}
$$

The flow value of being unemployed with assets $a$ is given by the utility flow from consumption $u(c)$ less the disutility of search effort $e(s)$ plus the expected change in the value of unemployment.

\footnotetext{
${ }^{10} \mathrm{~A}$ general model with additional stochastic non-labor income is outlined in Appendix B.

${ }^{11}$ See Appendix A for a derivation of equation (5) as the limit of the discrete time Bellman equation.
} 
The latter has two parts. First, the value of unemployment changes because assets change due to accumulation (or decumulation). This is the term $U_{a}(a)[r a+b-c]$ : the marginal value of assets times the instantaneous change in assets. Second, the value of being unemployed changes in probability by the product of the arrival rate of job offers and the expected net gain associated with job offers: $\lambda s \int \max \{W(a, x)-U(a), 0\} d F(x)$. When employed, the flow value of employment will also change in expectation by the product of the job destruction rate and the the net loss associated with losing wage $w: \delta[U(a)-W(a, w)]$.

In the formulation of the workers' problem I asserted that there is a lower bound on assets $\underline{a}$. This lower bound is not an exogenous liquidity or borrowing constraint, but rather a choice made by workers in an environment characterized by imperfect markets. Aiyagari (1994) demonstrates that a binding present value budget constraint combined with nonnegativity of consumption is equivalent to the period budget constraint $\underline{a}=-b / r$. I use this same argument, augmented to admit the possibility of a minimum necessary level of consumption $\zeta$.

Proposition 1 Under the assumptions that the present value budget constraint must hold, there is no possibility of default, and a minimum consumption level $\zeta$ exists such that $\lim _{c \rightarrow \zeta} u^{\prime}(c)[c-\zeta]=$ $\infty$, there is a self-imposed borrowing limit defined by $\underline{a}=(\zeta-b) / r$.

Workers will choose to limit their borrowing so as to avoid consumption falling below the minimum necessary level $\zeta$, even if they remain unemployed for an extended period of time. There are natural boundaries for such a minimum consumption level: $0 \leq \zeta \leq b$. In the case in which $\zeta=b$ workers will never borrow. In the case where $\zeta=0$ the most any worker will choose to borrow is an amount such that if he is so unlucky as to remain unemployed forever his interest payments would not exceed his unemployment benefit, keeping consumption positive. ${ }^{12}$

I now turn to the discussion of optimal search effort and optimal consumption choices for workers. The first order necessary conditions for optimal consumption and search effort when

\footnotetext{
${ }^{12}$ The possibility of a minimum necessary level of consumption ensures that some portion of the unemployment benefit is inalienable, precluding the counter-factual implication that some workers would use their entire benefit simply to pay interest on loans. Andolfatto (2002) develops a theory for endogenous legal institutions enforcing inalienable property rights in a setting with heterogeneous preferences. Here, homogeneous workers agree on the necessary consumption floor, and there is no need for additional legal constraints.
} 
unemployed and employed are:

$$
\begin{aligned}
u^{\prime}(c) & =U_{a}(a), \\
e^{\prime}(s) & =\lambda \int \max \{W(a, x)-U(a), 0\} d F(x), \\
u^{\prime}(c) & =W_{a}(a, w), \\
e^{\prime}(s) & =\lambda \int \max \{W(a, x)-W(a, w), 0\} d F(x) .
\end{aligned}
$$

Conditions (6) and (8) requires the marginal utility flow of consumption to be equal to the marginal value of assets, both when unemployed and unemployed. This is the standard inter-temporal result that expected utility can't be increases by additional savings or borrowing. Conditions (7) and (9) requires the marginal cost of search effort to be equal to the expected change in value associated with an accepted wage offer. Search effort is chosen such that expected utility can't be increases by exerting more or less effort.

In addition to making consumption and search effort decisions, unemployed workers must decide on the minimum wage offer that will induce a move from unemployment to employment. This reservation wage is the unique solution to $W(a, R(a))=U(a)$.

Proposition 2 The reservation wage for unemployed workers is independent of assets and equal to the unemployment benefit: $R(a)=b$.

The constant reservation wage is a direct consequence of the fact that the job contact rate $\lambda$ and the disutility of search $e(s)$ do not depend on the worker's employment status. Since there is no option value associated with remaining unemployed, any wage higher than the unemployment benefit is acceptable. Although the reservation wage is constant and independent of assets, the transition rate out of unemployment varies with assets because search effort varies with assets; optimal search effort is characterized by the differential equation

$$
s=\varphi\left(\lambda \int_{w}^{\bar{w}} \frac{u^{\prime}(c)+\left[u^{\prime \prime}(c) c_{w}\right][r a+x-c]}{\rho+\delta+\lambda s \bar{F}(x)} \bar{F}(x) d x\right)
$$

where $\varphi$ is the inverse function for the marginal cost of search $e^{\prime}(s)$.

The advantage of modeling endogenous search effort rather than using a separate contact rate when unemployed and employed is that the model implies that both unemployment and job durations are increasing in current assets, with job durations also increasing in the current wage, a 
feature that turns out to be empirically relevant. ${ }^{13}$

Proposition 3 Search effort is monotonically decreasing in both assets and the wage, declining from a maximum at $\{\underline{a}, \underline{w}\}$ and attaining a minimum of zero at the highest wage $\bar{w}$.

The monotonic relationship between search effort and assets is a consequence of the separability between utility of consumption and disutility of search effort. This separability is desirable for two reasons: it implies durations are increasing in assets, which is empirically supported in the data, and it provides analytical tractability.

I am now in the position to characterize optimal consumption growth (equivalently, optimal asset accumulation). Optimal consumption growth is characterized by the differential equation for consumption $^{14}$

$$
\frac{\dot{c}}{c}=\frac{1}{\gamma(c)}\left(r-\rho-\lambda s\left(\bar{F}(w)-\int_{w}^{\bar{w}} \frac{u^{\prime}(\hat{c})}{u^{\prime}(c)} d F(x)\right)+\delta\left(\frac{u^{\prime}(\underline{c})}{u^{\prime}(c)}-1\right)\right),
$$

the equation for asset accumulation

$$
\dot{a}=r a+w-c,
$$

and the present-value budget constraint

$$
\lim _{t \rightarrow \infty} \mathrm{e}^{-r t} a(t) \geq 0, \text { (a.s.) }
$$

where $\dot{x}=d x / d t, \gamma(c)=-u^{\prime \prime}(c) c / u^{\prime}(c)$ is the coefficient of relative risk aversion, and I make use of the shorthand $\bar{F}(w)=[1-F(w)], \hat{c}=c(a, x)$, and $\underline{c}=c(a, \underline{w})=c(a, b)$. Since all workers will reject wage offers below the common reservation wage $b$, any equilibrium wage offer distribution will have $\underline{w}=b$. Equations (10)- (13) must hold at all times, meaning that at the instant a new wage offer is accepted, or a job is destroyed, search effort and consumption must change discretely to ensure the worker is on the saddle path implied by the new wage.

\footnotetext{
${ }^{13}$ In the current context there is an additional technical advantage to this formulation. If the contact rate differed with the employment state the value function would contain a kink, making the use of the first order conditions for consumption invalid. Endogenous search effort retains the empirical content that unemployed workers contact firms at a higher rate, without introducing kinks into the value function.

${ }^{14}$ For other derivations of optimal consumption in the face of Poisson uncertainty see Merton (1971) for a model in which earnings are incremented upward by a fixed amount at random intervals, Wälde (1999) for a model where the capital gain from an R\&D investment is realized at random intervals, and Toche (2005) for a model of precautionary savings where the risk to labor income takes the form of exogenous retirement.
} 
The consumption growth equation (11) provides a direct and intuitive link between the labor market frictions $\lambda$ and $\delta$ and the motives for saving or dis-saving of workers at various points in the earnings distribution, as described by the following proposition:

Proposition 4 The job contact and job destruction rates have opposing influences on the incentive to save or dis-save, they affect the behavior of workers at different points in the earnings distribution differently, and the tension from these opposing forces results in a target level of savings that depends on the current wage.

Examination of equation (11) reveals the effect of the "wage ladder" on the savings behavior of workers at different points of the earnings distribution.

1. As in a perfect certainty environment, $r-\rho$ represents the importance of the rate of the time preference relative to the interest rate in determining savings.

2. $\lambda$ represents the potential for wage growth and induces additional impatience over and above the pure rate of time preference $\rho$. The influence of expected wage growth is greatest at the lowest wage $\underline{w}$ and falls monotonically as the wage increases, having no effect at the highest wage $\bar{w}$.

3. $\delta$ represents the risk of job loss, and induces precautionary savings. The effect of unemployment risk greatest at the highest wage $\bar{w}$ and falls monotonically, having no effect at the lowest wage $\underline{w}$.

4. Given any wage $w$ there is a target asset level $a^{*}(w)$ that balances the competing influences in 1) 2) and 3). Once $a^{*}(w)$ is attained, the worker will maintain a constant consumption level, equal to wage plus interest income, until he either switches jobs or becomes unemployed. ${ }^{15}$

The key to generating heterogeneity in savings is that expected gains and losses in income are not symmetric, and differ according to the current wage. Workers in the lowest paying jobs expect to gain much more when offered a new job than they expect to lose if the job is lost; this results in a desire to bring future income forward. Conversely, workers at the highest paying jobs have very little expectation of wage growth, but will lose a lot in the event of job loss, resulting in a strong motive to build up precautionary savings as an means to insure consumption across this transition.

\footnotetext{
${ }^{15}$ Carroll (2004) proves the existence of a target level of savings in a discrete time framework, a result that had previously been a robust feature of simulations but not proven generally.
} 


\subsubsection{Phase Diagram Characterization of Optimal Consumption}

The dynamics of consumption and savings can be seen clearly in the phase diagrams plotted in Figure 1. Defining the time derivative $\dot{a}=d a / d t$, the $\dot{a}=0$ and $\dot{c}=0$ loci are given respectively by the equations:

$$
\begin{aligned}
& c(a, w)=w+r a, \\
& c(a, w)=\phi\left(\frac{\lambda s \int_{w}^{\bar{w}} u^{\prime}(c(a, x)) d F(x)+\delta u^{\prime}(c(a, \underline{w}))}{\rho+\lambda s \bar{F}(w)+\delta-r}\right),
\end{aligned}
$$

where $\phi$ is the inverse function of the marginal utility of consumption $u^{\prime}(c)$. The target level of assets $a^{*}(w)$ is found by equating equations (14) and (15). For the existence of a stable saddle-path equilibrium it is necessary that $\rho>r-\delta-\lambda s \bar{F}(w)$. This condition must hold at all wage levels and thus collapses to $\rho>r-\delta .{ }^{16}$

In Figure 1(a) I plot the consumption and savings dynamics for an unemployed individual. Given assets $a$ at the time of job loss, an unemployed worker will smoothly draw down assets and reduce consumption. From Proposition 3, we know that search effort will rise as assets fall, resulting in an increasing probability of exiting unemployment. thus the model predicts the expected duration of an unemployment spell is positively correlated with the level of assets at the beginning of the spell. In Figure 1(b) I plot the consumption and savings dynamics of a worker employed at wage $\tilde{w}$. In this case, whether the worker saves or draws down assets will depend on the asset level at the time the job was initially accepted. If initial assets are below $a^{*}(\tilde{w})$ the worker will save, since his current assets are not high enough to provide sufficient insurance against income loss in the event of job destruction. If initial assets are above $a^{*}(\tilde{w})$ the worker will draw down assets, since the current asset level is more than sufficient to provide the desired level of insurance, and the desire for current consumption kicks in. Effort spent searching for a better paying job is decreasing the former case and increasing in the latter.

In the next proposition, the target asset level of a worker employed at the highest wage is examined. This level determines the upper bound on assets.

Proposition 5 Under the assumption that workers are sufficiently impatient $(\rho>r-\delta)$, the upper

\footnotetext{
${ }^{16}$ Variants of this condition can be found in Merton (1971) and Deaton (1991) for environments characterized by various exogenous stochastic processes for income.
} 
bound on desired assets is finite, and defined implicitly by the equation

$$
\bar{w}+r \bar{a}=\phi\left(\frac{\delta u^{\prime}(c(\bar{a}, \underline{w}))}{\rho+\delta-r}\right) .
$$

If $\rho-r$ is small relative to $\delta$ this collapses to

$$
\bar{w}+r \bar{a}=c(\bar{a}, \underline{w}) .
$$

The upper bound on assets is determined endogenously by the desire to smooth the marginal utility of consumption across employment states. When $\rho-r$ is small relative to $\delta$ workers at the highest wage save up to the point at which they can prevent a discrete change in consumption at the instant of a job loss.

It is worth noting that, in the derivation of optimal consumption growth and search effort, individual workers take the wage offer distribution $F(w)$ as given. The workers do not care how the offer distribution arises in equilibrium, only that they know what it looks like. This feature is important in that the analytical results concerning optimal savings behavior do not depend on the particular wage determination process; they only depend on the existence of a dispersed offer distribution. This makes it possible to separate the analysis of worker behavior from that of the firms and from the particular mechanisms generating the equilibrium wage offer distribution. In the following section I develop the dispersed offer distribution as the result of profit maximizing behavior on the part firms engaged in wage posting. ${ }^{17}$

\subsection{The Firms' Problem}

In an environment characterized by informational frictions, on-the-job search, and the possibility for jobs to terminate exogenously, Burdett and Mortensen (1998) show that if firms post wages, the only equilibrium consists of a continuous distribution of posted wages. The intuition behind this result is simple. Assume all firms have the same productivity level, and can produce output $p$ per worker employed. If a firm posts a low wage, it will earn a high profit from each worker it employs, but these workers will quickly leave for higher paying jobs at other firms. If a firm posts

\footnotetext{
${ }^{17}$ An obvious alternative to wage posting is wage bargaining. Shimer (2006) demonstrates that wage dispersion can also exist in an on-the-job search model with bargained wages. However, the workers' problem remains unchanged regardless of whether $F(w)$ is the result of posting or bargaining (assuming that the bargaining is unaffected by a worker's asset level). The advantage of bargaining is the potential to introduce aggregate uncertainty in a tractable way. This however comes at the cost of multiple equilibrium in the wage determination.
} 
a high wage, it will earn a smaller profit, but for a longer period of time, since workers will be less likely to find better paying jobs. In the equilibrium, the expected profit from the low wage-high turnover policy must be equal to the high wage-low turnover policy. Since an equilibrium requires no profitable deviations, the dispersed wage offer distribution is the unique solution such that all firms earn equal expected profits.

It is well known that the basic Burdett-Mortensen model with homogeneous workers and homogeneous firms generates dispersed wages, but it has counter-factual implications for the shape of the wage distribution. The addition of firm heterogeneity can make the equilibrium search model consistent with the empirical shape of the wage distribution. Bowlus, Kiefer, and Neumann (1995, 2001) estimate the model with discrete firm heterogeneity and find that adding a small number of discrete productivity levels vastly improves the ability of the model to match the empirical earnings distribution. The advantage of using discrete heterogeneity is that it still admits the possibility of dispersion in wages across firms of the same type. The cost is that it makes the estimation problem non-standard. Bontemps, Robin, and van den Berg (1999, 2000) derive and estimate the BurdettMortensen model with continuous heterogeneity in firm productivity. In this case, wage offers will be a one-to-one function of productivity, $w=w(p)$, and the fraction of wage offers at or below $w(p)$ is simply the fraction of employers with productivity at or below $p$,

$$
F(w(p))=\Gamma(p)
$$

The advantage of the approach outlined by Bontemps, Robin, and van den Berg is that it does not introduce any non-standard issues into the estimation problem.

Since the primary goal of this paper is to analyze the joint distribution of observed wages and assets of workers, I will work with continuous heterogeneity in firm productivity, which will be treated as exogenous. Continuous heterogeneity provides a convenient method to obtain the empirical shape of the earnings distribution without introducing additional complications in the estimation. Firm heterogeneity will be recovered as the distribution that produces the offer distribution necessary to generate the observed joint distribution of assets and wages. In the next section I demonstrate that the offer distribution can be recovered by invoking the implications of a stationary equilibrium. 


\subsection{Steady-State Worker Flows}

In steady-state the flow of workers into and out of unemployment must be equal. Additionally, the flows of workers into and out of jobs paying $w$ or less must be equal. Imposing these conditions allows one to write the wage offer distribution as a function of accepted wages, search effort, and the joint density of assets and wages, as outlined in the following proposition:

Proposition 6 With observations on individual accepted wages and assets but not wage offers, we can recover the wage offer distribution as:

$$
F(w)=\frac{\delta G(w)+\lambda \int_{b}^{w} \int_{\underline{a}}^{\bar{a}} s(x, y) h(x, y) d x d y}{\delta+\lambda \int_{b}^{w} \int_{\underline{a}}^{\bar{a}} s(x, y) h(x, y) d x d y}
$$

with corresponding density

$$
f(w)=\frac{\delta g(w)+\lambda \bar{F}(w) \int_{\underline{a}}^{\bar{a}} s(x, w) h(x, w) d x}{\delta+\lambda \int_{b}^{w} \int_{\underline{a}}^{\bar{a}} s(x, y) h(x, y) d x d y} .
$$

\subsection{Equilibrium}

Definition A stationary equilibrium is characterized by pair of policy functions $\{c(a, w), s(a, w)\}$, a wage offer distribution $F(w)$, and a joint distribution of assets and wages $H(a, w)$ such that

1. Given the wage distribution $F(w)$ and the market frictions $\lambda$ and $\delta$, the policy functions $c(a, w)$ and $s(a, w)$ are the solution to the workers' maximization problem (equations (4) and (5)).

2. The workers' policy functions $c(a, w)$ and $s(a, w)$ and the wage offer distribution $F(w)$ induce the stationary joint distribution of assets and wages $H(a, w)$.

3. The wage offer distribution $F(w)$ satisfies the steady state worker flow condition given by equation (19).

\section{Implications of the Model}

Several interesting cross-sectional implications arise from the workers' consumption growth equation (11). Rewrite the consumption growth (equivalently, the asset accumulation) equation in terms 
of the interest rate and an individual specific "discount rate" $\rho_{i}$, where $i$ indexes individuals and

$$
\rho_{i}=\rho+\lambda s_{i}\left(\bar{F}\left(w_{i}\right)-\int_{w_{i}}^{\bar{w}} \frac{u^{\prime}\left(c\left(a_{i}, x\right)\right)}{u^{\prime}\left(c\left(a_{i}, w_{i}\right)\right)} d F(x)\right)-\delta\left(\frac{u^{\prime}\left(c\left(\underline{w}, a_{i}\right)\right)}{u^{\prime}\left(c\left(a_{i}, w_{i}\right)\right)}-1\right) .
$$

Now the right hand side of equation (11) becomes $\gamma^{-1}\left(r-\rho_{i}\right)$, where individuals are all "discounting" at a different rate, and as a result, have very different savings behavior. Written in this form there is a close relationship to the stochastic discount rates used by Krusell and Smith (1998), where individuals are heterogeneous in their rate of time preference, leading to a very unequal wealth distribution. There is, however, an important distinction between the two setups. In the Krusell and Smith setup, individuals are poor or rich (in terms of wealth) because they either have a high or low rate of time preference; they prefer to be poor or rich. In contrast, in the current setup, all workers have identical preferences, and they would behave identically in the same circumstances; the differences across individuals arise from different sequences of good and bad luck in the labor market.

\section{Solving the Model}

Given a set of structural parameters, the model described in Section 2 is solved numerically. For the purpose of the numerical solution, and for estimation, it is necessary to specify a functional form for the utility of consumption and the costs of search effort. I assume a power form for both utility and search costs. Specifically, I use a constant relative risk aversion utility function, modified to include the possibility of a minimum necessary level of consumption,

$$
u(c)= \begin{cases}\frac{(c-\zeta)^{1-\gamma}}{1-\gamma}, & \gamma>0 \\ \log (c-\zeta), & \gamma=1\end{cases}
$$

where $\gamma$ is the coefficient of relative risk aversion and $\zeta$ is the minimum necessary level of consumption. I assume the search cost function has the following form,

$$
e(s)=\alpha \frac{s^{1+1 / \eta}}{1+1 / \eta}
$$

with $\eta>0$ to ensure convexity, where $\alpha>0$ is a scaling parameter. The elasticity of search costs with respect to effort is $1+1 / \eta$.

I proceed with the numerical solution in two steps. Given a guess at the wage offer distribution, I solve the workers' dynamic programming problem (equations (4)-(7)). The solution to the workers' problem provides policy functions for consumption and search effort. The policy function for 
search effort is then used to calculate the equilibrium offer distribution (equation (19)). If the offer distribution calculated in this manner is equal to the original guess, I stop. Otherwise I update the guess of the offer distribution as a convex combination of the original guess and the implied equilibrium distribution. I repeat these steps until the policy functions implied by the guess reproduce the offer distribution, to some fixed tolerance level. ${ }^{18}$

The dynamic programming problem laid out in Section 2.2 is expressed in continuous time, and is continuous in the state variables. Since it is not possible to solve an infinite dimensional problem numerically, I use a set of interpolation techniques that are well suited to addressing this problem. The value functions are approximated using Chebyshev collocation. This method is discussed in detail by Judd (1998, chs. 6, 11). The basic idea behind the method is to approximate the unknown value function by the closest function in polynomial space. The approximations to the value functions in equations (4) and (5) are then written as zero functions and solved for exactly at a discrete set of grid points. Working in continuous time in this context has several advantages. First, it enables me to derive an analytical form for the consumption dynamics in equation (11). Second, the first order conditions (equations (6) and (7)) are expressed solely in terms of instantaneous marginal utility of consumption and the instantaneous marginal value of assets. This alleviates the need for a numerical search algorithm over optimal consumption and search effort that would be required in a discrete time framework. The policy functions can be computed directly from the first order conditions. The grid points are chosen as the zeros of the Chebyshev polynomials; this choice of polynomial representation and choice of grid points ensures the numerical problem is well conditioned. I outline the details of the approximation method in the current context in Appendix D.1. ${ }^{19}$ One additional advantage of the collocation approach is that the residual error can be calculated for points off the grid used in the solution. With a grid comprising only 4 nodes for wages and 5 nodes for assets, the maximum residual error (measured as the approximation error relative to the function) is on the order of $10^{-5}$.

\footnotetext{
${ }^{18}$ Preliminary results avoid the demanding task of solving for the equilibrium offer distribution by substituting a nonparametric estimate of the offer distribution based on accepted wages out of unemployment. While this is a consistent estimate, and dramatically reduces the computational burden of solving the model, it precludes conducting policy experiments until the offer distribution is solved for as a function of structural parameters as given by equation (19).

${ }^{19} \mathrm{~A}$ second numerical issue is that the value function and the policy functions are quite non-linear in assets and wages. To gain additional numerical accuracy, I transform the variables such that the value function is approximately linear in the transformed variables. I provide the details of the transformation in Appendix D.2.
} 


\section{Data}

The data for this analysis are from the National Longitudinal Survey of Youth 1979 (NLSY79). The NLSY79 consists of 12,686 individuals who were 14 to 21 years of age as of January, 1979. The NLSY79 contains a nationally representative random sample, as well as an over-sample of black, Hispanic, the military, and poor white individuals. A complete labor market history, by week, can be constructed for each individual in the sample. The labor market history provides the potential of over 1,300 weekly observations per individual, including the current weekly earnings, transitions to and from unemployment and between jobs. Since 1985, the NLSY contains detailed questions on the asset holdings of each individual. The asset data are not observed at the same frequency as the labor market data. From 1985 onward, asset data are collected at interview dates, providing at most one observation on assets per year. I discuss the estimation issues arising from this partially observed state variable in Section 6.

I use the white male sample from the NLSY79 data. The restriction of attention to white males is motivated by an attempt to create a relatively homogeneous subgroup that is well described by the model developed in the paper. Since the schooling decision is exogenous to the model, I only include data for individuals once they have completed their education. I also drop individuals who have served in the military, or have identified their labor force status as out of the labor force. ${ }^{20}$ I subdivide the data into two education groups: those with a high school degree, and those with a college degree. I do not use data on high school dropouts and college dropouts. ${ }^{21}$ Since not all individuals finished school at the same time, and some have dropped out of the survey, I am left with an unbalanced panel of 779 high school graduates (405,931 person weeks), and 555 college graduates $(235,350$ person weeks). With working and unemployed as the only two labor force states in the model, I need to choose a cutoff for the number of hours that qualify as employed. I follow Bowlus, Kiefer, and Neumann (2001) and define employment as working 35 hours or more a week.

Monetary variables are adjusted for inflation using the GDP deflator. To reduce the influence of outlying observations, I trim the top and bottom one-half-of-one percent of the wage and as-

\footnotetext{
${ }^{20}$ The majority of individuals who are not in the labor force report being disabled and are clearly not searching for employment. Without an additional state for disability, the model has nothing to say about such individuals.

${ }^{21}$ The summary statistics for these groups are too different from either included group to pool them, and the sample sizes are too small to use on their own.
} 
set observations. I follow the definition of total assets used by Keane and Wolpin (2001) and Imai and Keane (2004): I construct total assets (net worth) by adding up the following variables in the NLSY: "Total market value of vehicles including automobiles r/spouse own," "Total market value of farm/business/other property r/spouse own," "Market value of residential property r/spouse own," "Total market value of stocks/bonds/mutual funds," "Total amount of money assets like savings accounts of r/spouse," "Total market value of all other assets each worth more than \$500." From this I subtract the total of “Total amount of money r/spouse owe on vehicles including automobiles," "Total amount of debts on farm/business/other property r/spouse owe," "Amount of mortgages and back taxes r/spouse owe on residential property," "Total amount of other debts over $\$ 500$ r/spouse owe."

In the next section, I describe the NLSY79 data, and provide details of the correlations and joint distributions of the variables of theoretical interest: wages, assets, and employment and unemployment durations.

\subsection{Descriptive Statistics}

The following features of the data are particularly relevant to exercise at hand:

1. Earnings are dispersed, with a mean much higher than the median.

2. Assets are even more unequal than earnings

3. By the end of the sample the wage distribution has converged to a stationary distribution.

4. Job durations are positively correlated with both wages and asset levels at the beginning of the job.

5. Unemployment durations are positively correlated with asset levels at the beginning of the spell.

I discuss each of these features in turn.

Table 1 provides summary statistics for the data used in the analysis. The statistics are reported for the end of the sample period (week 1269), by which time it is presumed that the distribution of wages has converged to its stationary distribution. Support for convergence is provided in the next 
paragraph. In the left hand column I provide the statistics for the raw sample, and in the right hand column the same statistics with the top and bottom 0.5 percent trimmed. The extreme observations in the raw data are an order of magnitude larger than in the trimmed data. Removing them greatly reduces the variance but has little impact on the mean and median. For both the wage and the asset data the mean is much higher than the median, with the ratio of mean to median much greater for assets than for wages.

The model developed in Section 2 assumes that the wage offer distribution, and by implication the accepted wage distribution, is stationary. Since the NLSY sample is a cohort, the wage distribution at the beginning of the period is not expected to be stationary. The appropriate counterpart to the cohort data in the model is a sample of workers who are all observed in unemployment, and over time become employed and move up the wage ladder. As time progresses, the wage distribution for this subsample will converge to the stationary distribution. In Figure 2, I plot the empirical distribution of wages every four years from 1978 to 2002. By 1998 the distribution appears to have converged, as the empirical CDFs for 1998 and 2002 lie directly on top of each other. Using a Kolmogorov-Smirnov test for the equality of two distributions, I do not reject the null hypothesis that the distributions in 1998 and 2002 are equal, while I do reject this hypothesis for any other pair of years. I take this as evidence supporting the assumption that the wage distribution is stationary.

In Figure 3, I present the joint distribution of wages and assets. The top panels contain scatter plots of assets and wages for the two education groups. It is worth noting that there are some observations where assets are very high and wages are low, and some where wages are high and assets are low. In the bottom panels, I plot kernel density estimates of the joint distribution. ${ }^{22}$ The contour lines for the joint density are drawn at equally spaced heights for the joint PDF. This implies that where the lines are close together, the slope of the density is very steep, and conversely, the slope is flatter the further apart are the contour lines. Along the earnings dimension, the long right tail is clear. Looking along the asset dimension, it is clear that the density rises steeply from small negative assets to moderate positive assets, and then declines, rapidly at first and then slowly. Median assets are $\$ 67,618$ for the high school group and $\$ 187,366$ for the college educated (Table 1). The corresponding maximum assets are, respectively, $\$ 1$ and $\$ 4.2$ million. Even within

\footnotetext{
${ }^{22}$ The kernel (Epanechnikov) is applied to the data after applying a log-type transformation. The transformation is $\mathcal{A}=\log (a-\underline{a}+1)$ and $\mathcal{W}=\log (w+1)$. The data are then transformed back to levels for the figure. This transformation is discussed in detail in Appendix D.2, and is also used in the solution of the model to improve the numerical approximations.
} 
the education groups, there is a very high degree of dispersion in earnings and wealth.

Survival curves for job durations and unemployment durations are presented in Figure 4. The survival curves are plotted separately by education level, and within education level, separately by the position in either the wage or asset distribution. For the first row, Figures 4(a) and 4(b), workers are divided into three groups, according to whether their wage at the current job is in the top decile, the bottom decile, or the middle 80 percent of the wage distribution. I then plot the Kaplan-Meier survival functions for each group. Workers are considered to exit when they quit to take another job; if they transit to unemployment I treat the spell as censored. For both education groups, only half of the workers with wages in the bottom decile remain employed at the same job after 18 months; the rest have changed jobs. In contrast, half of the workers with wages in the top decile remain with the same employer at least 11 years.

I repeat this exercise, this time grouping workers according to their position in the asset distribution, and plot the results in Figures 4(c) and 4(d). ${ }^{23}$ The same pattern emerges when individuals are grouped by their positions in the asset distribution. Workers with low assets switch to other jobs at a much higher rate than workers with high assets. Job durations are positively correlated with wage and asset levels. This correlation is consistent with the theory developed in Section 2.2, which shows that search effort (and therefore the probability of finding a new job) is decreasing in both the current wage and asset level.

In the bottom panel, Figures 4(e) and 4(f), I repeat the exercise for unemployment durations. Most unemployment durations are very short; half of these durations last for less than 12 weeks. For the college educated group, the same pattern of longer spells associated with higher assets appears to be present. For the group with high school education, the survival curves cross, with slightly more long-term spells associated with the high asset group. However, in both cases the differences are not statistically significant. The unemployment rate for prime age white men is very low. Thus there may simply be too few unemployment spells, with even fewer long term unemployment spells, to make inference about differences in unemployment survival probabilities using this data set.

\footnotetext{
${ }^{23}$ Assets are rarely observed exactly at the beginning of the job spell. I use the asset level as close as possible to the start of the spell. An alternative is to use the asset level observed prior to the spell. This has the advantage of removing the endogeneity of the asset level to the current spell, but comes at the cost of losing a lot of data, and hence a lot of precision.
} 


\section{Estimation}

In this section, I outline two strategies for estimation, both of which involve simulation-based estimators. The first is a maximum simulated likelihood approach, and the second is an indirect inference approach. In Section 5 I noted that the NLSY data provides weekly data on each individual's current employment status, wage, and whether the worker continued the next week at the same job, a new job, or transited to unemployment. I also noted that the asset data are provided only at the interview date, which is at most once a year. The fact that assets are only partially observed, at irregularly spaced interview dates, is the main issue that needs to be overcome in the estimation strategy. Both simulation based estimators can cope with this problem.

\subsection{Maximum Simulated Likelihood}

Abstracting for the moment from the issue of partially observed asset data, the model directly provides the probability of observing any particular history of job and unemployment spells, conditional on the structural parameters. The probability of transiting to a better paying job is given by the product of the job contact rate $\lambda$, search effort as a function of assets and the wage $s(a, w)$, and the probability that a contacted firm is paying a higher wage $\bar{F}(w)$ (equal to one when unemployed). When employed, the probability of becoming unemployed is $\delta$. Given weekly data on labor force status, current wages, and current asset levels, the contribution of an individual's labor market history to the likelihood function can be broken into spells of unemployment of duration $T_{j}$ and spells of employment of duration $T_{k}$ and $T_{l}$, where the distinction between $k$ and $l$ is whether the spell ended in a transition to another job or a transition to unemployment, respectively. These contributions are

$$
\begin{aligned}
\mathcal{L}_{U, i}(\theta) & \left.=\prod_{t=1}^{T_{j}-1}\left(1-\lambda s\left(a_{i, t}, b\right)\right) \times \lambda s\left(a_{i, T_{j}}, b\right)\right), \\
\mathcal{L}_{E E, i}(\theta) & =\prod_{t=1}^{T_{k}-1}\left(1-\left(\delta+\bar{F}\left(w_{i, t}\right) \lambda s\left(a_{i, t}, w_{i, t}\right)\right)\right) \times \bar{F}\left(w_{i, t}\right) \lambda s\left(a_{i, T_{k}}, w_{i, t}\right) f\left(w_{i, T_{k}}\right), \\
\mathcal{L}_{E U, i}(\theta) & =\prod_{t=1}^{T_{l}-1}\left(1-\left(\delta+\bar{F}\left(w_{i, t}\right) \lambda s\left(a_{i, t}, w_{i, t}\right)\right)\right) \times \delta
\end{aligned}
$$


where $E E$ and $E U$ refer, respectively, to employment-to-employment transitions and employmentto-unemployment transitions, and $\theta$ represents the vector of structural parameters to be estimated. ${ }^{24}$

In the NLSY, assets are only partially observable. I do not have weekly observations on the $\left(a_{i, t}, w_{i, t}\right)$ pairs, and I therefore cannot directly calculate $s\left(a_{i, t}, w_{i,}\right)$ for all $t$. Here, I follow the strategy of Keane and Wolpin (2001) and use the model to simulate the path of assets. Combined with the assumption that assets in the data are measured with error, this strategy simultaneously addresses the issue of partially observed data and provides a likelihood contribution for the asset data. I assume that the measurement error has the form $a_{i, t}^{d}=a_{i, t} \varepsilon_{i, t}$ with $\log \left(\varepsilon_{i, t}\right) \sim i i d N\left(0, \sigma_{a}^{2}\right)$. The approach proceeds as follows:

1. For each individual, draw a measurement error $\varepsilon_{i}$.

2. Generate an initial asset level by dividing the asset level observed in the data by the measurement error: $a_{i, 0}=a_{i, 0}^{d} / \varepsilon_{i}$.

3. Using this initial asset $a_{i, 0}$, along with the weekly observations on the wage and job status, the model generates a simulated path for assets.

4. At each interview date $m$, I calculate the measurement error as the difference between the logarithms of the simulated and the observed assets. This provides the likelihood contribution for the observed sequence of assets for individual $i$ :

$$
\mathcal{L}_{a, i}=\prod_{m \in M} \phi\left(\frac{\log \left(a_{i, m}^{d}\right)-\log \left(\hat{a}_{i, m}\right)}{\sigma_{a}}\right)
$$

where $m$ indexes the week in which we observe the assets in the data, and $M$ is the collection of all of these weeks.

Since this a simulation-based estimator, I need to repeat the above procedure many times. For each individual $i$, I draw $R$ initial measurement errors $\varepsilon_{i}^{r}, r=1 \ldots R$, and create $R$ likelihood contributions. The simple average of these becomes the individual's likelihood contribution. Combining the contributions in (23) and (24), and indexing each simulation by $r$, the simulated likelihood contribution for individual $i$ is

$$
\mathcal{L}_{i}(\theta)=\frac{1}{R} \sum_{r=1}^{R} \prod_{T_{j} \in J} \mathcal{L}_{U, i}^{r}(\theta) \times \prod_{T_{k} \in K} \mathcal{L}_{E E, i}^{r}(\theta) \times \prod_{T_{l} \in L} \mathcal{L}_{E U, i}^{r}(\theta) \times \prod_{m \in M} \mathcal{L}_{a, i}^{r} .
$$

\footnotetext{
${ }^{24}$ It is possible to ignore the natural time ordering and regroup the spells this way because all the time dependence is fully captured through the state variable assets.
} 
A graphical depiction of a typical individual's likelihood contribution is sketched in Figure 5. Here, the contribution for one simulation $r$ comprises the probability of observing the pattern of job spells and wages depicted in the top panel (conditional on the simulated asset path in the bottom panel) and the contribution of the measurement error in assets depicted in the bottom panel.

\subsection{Indirect Inference}

An alternative to maximum simulated likelihood, is to use the indirect inference method proposed by Smith (1993) and Gourieroux, Monfort, and Renault (1993). This approach is closely related to the method of simulated moments of McFadden (1989) and Pakes and Pollard (1989), as well as to the simulated minimum distance method of Hall and Rust (2002, 2003). The idea is essentially the same as in calibration; moments from the data are selected, and the model parameters are estimated by choosing the parameters so that the simulated moments match the actual data moments. The method of indirect inference proceeds by estimating descriptive (as opposed to structural) models on both the actual data and on data simulated from the structural model. The descriptive models are chosen simultaneously to provide a rich description of the correlation patterns in the data and to be fast to calculate.

For the current application, descriptive models need to capture the effects of the search effort and consumption decisions. I use two regressions to capture the effect of wages and assets on search effort and consumption growth. The observable effect of search effort is that it reduces the expected length of an unemployment or job spell. The observable effect of consumption choices (at least in the NLSY data) is in terms of changes in asset levels between interview dates. I use the following two regressions to describe these correlations:

$$
\begin{aligned}
\log \left(T_{i, j}\right)= & \pi_{0}+\pi_{1} a_{i, j}+\pi_{2} a_{i, j}^{2}+\pi_{3} w_{i, j}+\pi_{4} w_{i, j}^{2} \\
& +\pi_{5} a_{i, j} w_{i, j}+\pi_{6} D_{i, j}+\operatorname{residual}_{i, j} \\
\frac{a_{i, n}-a_{i, m}}{a_{i, m}(n-m)}= & \pi_{7}+\pi_{8} a_{i, m}+\pi_{9} a_{i, m}^{2} \\
& +\pi_{10} w_{i, m}+\pi_{11} w_{i, m}^{2}+\pi_{12} a_{i, m} w_{i, m}+\pi_{13} D_{i, m}+\operatorname{residual}_{i, m}
\end{aligned}
$$

where $T_{i, j}$ is the duration, measured in weeks, of spell $j$ for individual $i, D_{i, j}$ is a dummy variable that takes on a value of one if the spell is an employment spell, and zero if the spell is an unemployment spell, and $m$ and $n$ refer to the number of the week in which an interview took 
place.

Regression (26) describes the duration of a job or unemployment spell as a polynomial function in the wage (benefit) during the spell, and the asset level observed at the beginning of the spell. This representation is meant to capture, in a parsimonious manner, the shapes of the survival functions plotted in Figure 4. Regression (27) describes the average growth of assets between interview weeks $m$ and $n$ as a polynomial function of the state variables observed in week $m$. To help identify the minimum necessary consumption level, which will have a direct influence on the amount of debt workers are willing to accumulate, I add a third regression to capture the fraction of individuals with negative assets,

$$
1\left(a_{i, m} \leq 0\right)=\pi_{14}+\text { residual }_{i, m}
$$

The fraction of workers holding negative assets is directly related to the lower bound on assets, which, combined with the lowest wage offered, identifies the minimum necessary consumption level $\zeta$.

Key to this estimation strategy is sampling from the model simulated data in exactly the same way as the actual data were sampled. I do this by simulating data for the same number of individuals as I observe in the NLSY, and for the same number of weekly observations per individual that are actually recorded in the NLSY. Additionally, I sample assets to create the average growth for equation (27) in the weeks that correspond to the actual interview week.

The structural parameters $\theta$ are estimated by minimizing the distance between the regression coefficients estimated on the actual data, and the average of the regression coefficients estimated on $R$ simulated data sets,

$$
\hat{\theta}=\arg \min _{\theta}\left(\hat{\pi}-\frac{1}{R} \sum_{r=1}^{R} \tilde{\pi}^{r}\right)^{\top} \Omega(\hat{\pi})^{-1}\left(\hat{\pi}-\frac{1}{R} \sum_{r=1}^{R} \tilde{\pi}^{r}\right),
$$

where $\Omega(\hat{\pi})$ is the covariance matrix for the regression coefficients estimated from the actual data.

\subsection{Two-Step Estimation Scheme}

Preliminary estimates are obtained through the use of a two-step estimation strategy that avoids solving for the equilibrium offer distribution at each parameter guess. This approach makes use of the fact that, in the model, workers only reject wage offers if they fall below their current wage. In 
the equilibrium, there are no offers below the common reservation wage of the unemployed; unemployed workers never reject wage offers. Given this implication, the distribution of wages accepted out of unemployment is a consistent estimate of the wage offer distribution. For the preliminary two-step estimation, I estimate the offer distribution non-parametrically using the wages accepted by unemployed workers. In the solution and estimation of the model, I then replace equations (19) and (20) with this non-parametric estimate.

I plot the estimate of the offer distribution, along with an estimate of the wage distribution in Figure 8. Looking at the estimated CDFs in the right-hand panel, the distinction between the wage offer and the accepted wage distributions is clear. A worker employed at the median wage will find that only ten percent of wage offers received are higher than his current wage, despite the fact that half of the labor force earns more than him.

\section{Quantitative Results}

In the estimation I hold fixed the risk-free rate $r$, the rate of time preference $\rho$, and the scale of the disutility of search effort $\alpha$. The risk free rate is set to an annual rate of three percent and the rate of time preference is set to five percent, both are standard values. I normalize the scale of the disutility of search effort, which is not separately identified from the job-offer rate $\lambda$, to $0.10 .^{25}$ Preliminary point estimates of the structural parameters based on indirect inference are presented in Table $2 .^{26}$

The estimates for the coefficient of relative risk aversion for high school and college educated are 1.44 and 2.35 respectively. Additional evidence that higher educated individuals have higher risk aversion can be found in Alan and Browning (2003). The minimum necessary level of consumption is estimated to be equivalent to approximately $\$ 590$ per month for low educated and $\$ 770$ per month for high educated. As a point of comparison, Meyer and Sullivan (2003, Table 2) estimates the average monthly consumption for US households in the bottom decile to be approximately $\$ 765$ per month. Search costs are estimated to be lower for high school educated than for college educated men; the elasticities are respectively 1.66 and 1.77, smaller than the quadratic specification often assumed. Using data on Danish firms, Christensen, Lentz, Mortensen, Neu-

\footnotetext{
${ }^{25}$ This scale is chosen for numerical accuracy, making the scale of the policy functions for consumption and search effort approximately equal.

${ }^{26}$ I defer formal statistical inference until the final estimates are available.
} 
mann, and Werwatz (2005), obtain a pooled elasticity of 1.89, and elasticities of 1.4 and 2.43 for skilled and unskilled workers respectively. Both the job contact rate and the job destruction rate are estimated to be higher for the low educated group. While the cost of search is estimated to be higher for college educated than for high school educated, the return is also higher, since both the average and the highest offered wages are higher.

The implication of these estimates in terms of the earnings and wealth distributions are presented in Table 3. The preliminary results are very promising. The model matches the Lorenz curve for wealth almost exactly; this is the case both within the education groups and also when they are pooled. The model does produce earnings dispersion, but slightly under predicts the degree of dispersion observed in the data. The model also tends to predict higher persistence in earnings and wealth than in the data.

In Figures 7(a) and 7(b), I plot Lorenz curves for wealth for the data and the model, by education group. The curve for the model lies virtually on top of the data for both groups. In Figure 7(c), I repeat this exercise, pooling the education groups. There is a substantial amount of inequality within the groups, and it is even higher when they are pooled. For reference, I also plot the Lorenz coordinates (top 1, 5, 10, 20, and 30 percent) for the entire US economy (+). While there is substantial dispersion in wealth across the subsample of the NLSY used in the current paper, it is considerably less than the degree in the entire US economy. This is due to the focus on a relatively homogeneous group: white males born between 1957 and 1965. Adding in more heterogeneous groups will certainly increase the overall level of inequality.

The success of the model in matching the inequality in wealth is largely attributable to the effect on savings behavior of the wage ladder induced by on-the-job search. This mechanism, which arises endogenously in the model, can readily be related to the work of Krusell and Smith (1998) and Castañeda, Díaz-Giménez, and Ríos-Rull (2003). In Section 3 I described the connection between the heterogeneous discount rate version of the model in Krusell and Smith (1998) and the model presented here. In the current framework, workers behave as if they have heterogeneous discount rates, and the resulting differences in savings behavior produces the large dispersion in wealth. The discussion surrounding Proposition 4 demonstrates the effect of the earnings dynamics on savings behavior. In particular, the incentive to save increases as the expectation of wage growth falls and as the income loss associated with job destruction increases. The wage ladder process 
for earnings, resulting from on-the-job search, implies that expected wage growth is declining in the current wage, and the income loss associated with job destruction is increasing in the current wage. The earnings process calibrated by Castañeda, Díaz-Giménez, and Ríos-Rull (2003) shares these features; the probability of obtaining a higher wage is decreasing in the current wage, and the income loss associated with exiting the highest wage is substantial.

\section{Conclusions}

In this paper, I show that a model of the labor market with on-the-job search and saving can account quantitatively for the joint distribution of earnings and wealth. I show that in a labor market characterized by informational frictions and the possibility of job destruction, workers with different wages will exhibit very different savings behavior; indeed they will behave as if they have heterogeneous discount rates.

The model parameters are estimated using simulation-based estimation. The parameters are estimated from micro-level observations on employment transitions, wage changes, and asset accumulation. Given these parameter estimates, data simulated from the model aggregates to replicate the degree of inequality in wealth observed in the NLSY.

Considering the good fit of both the micro-level and aggregate features of the data, the estimated structural model can be used to quantify the effects of counter-factual experiments—such as changes in unemployment benefits—on search effort and savings decisions of individuals, and on the aggregate levels of unemployment and wealth inequality. 


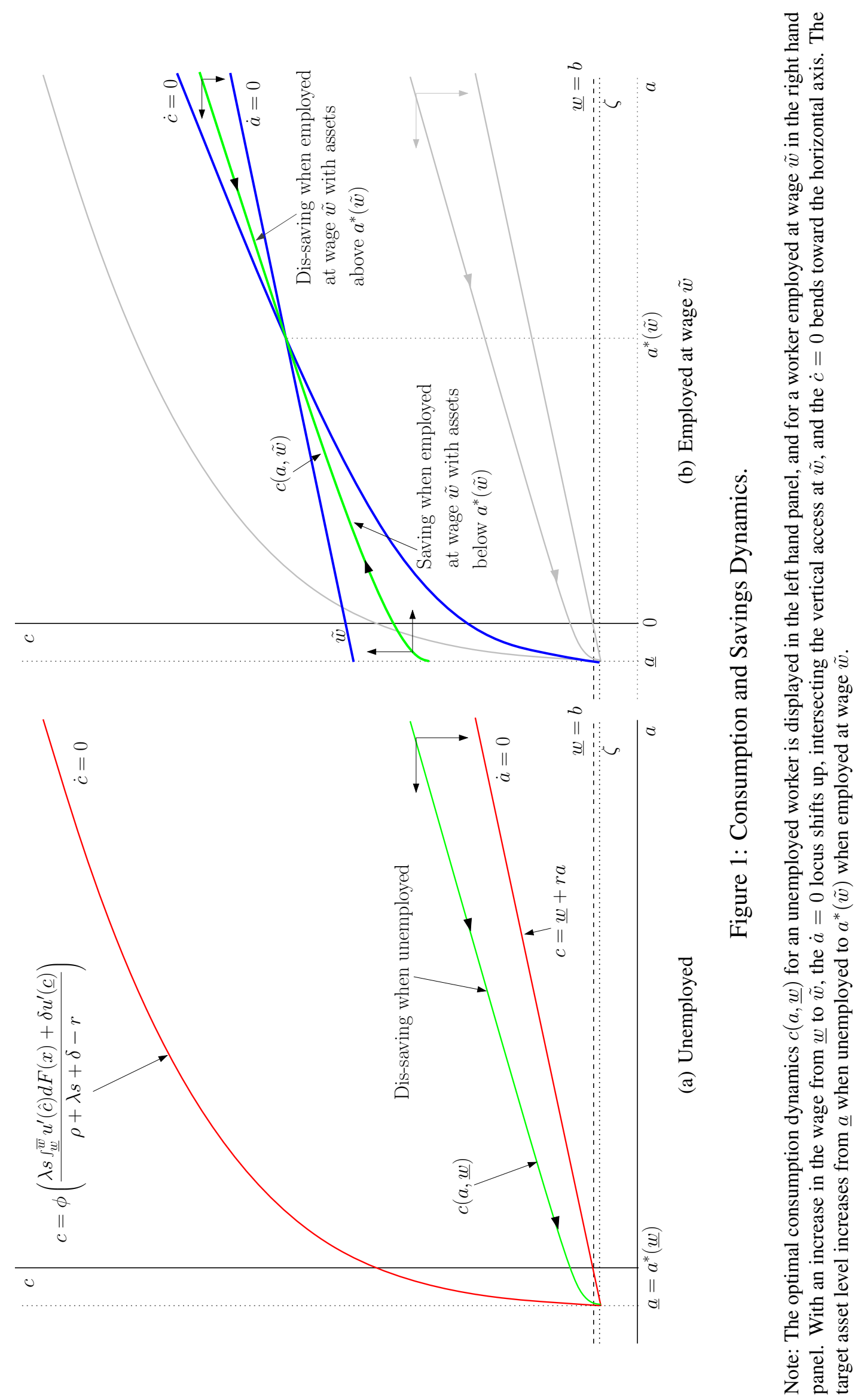




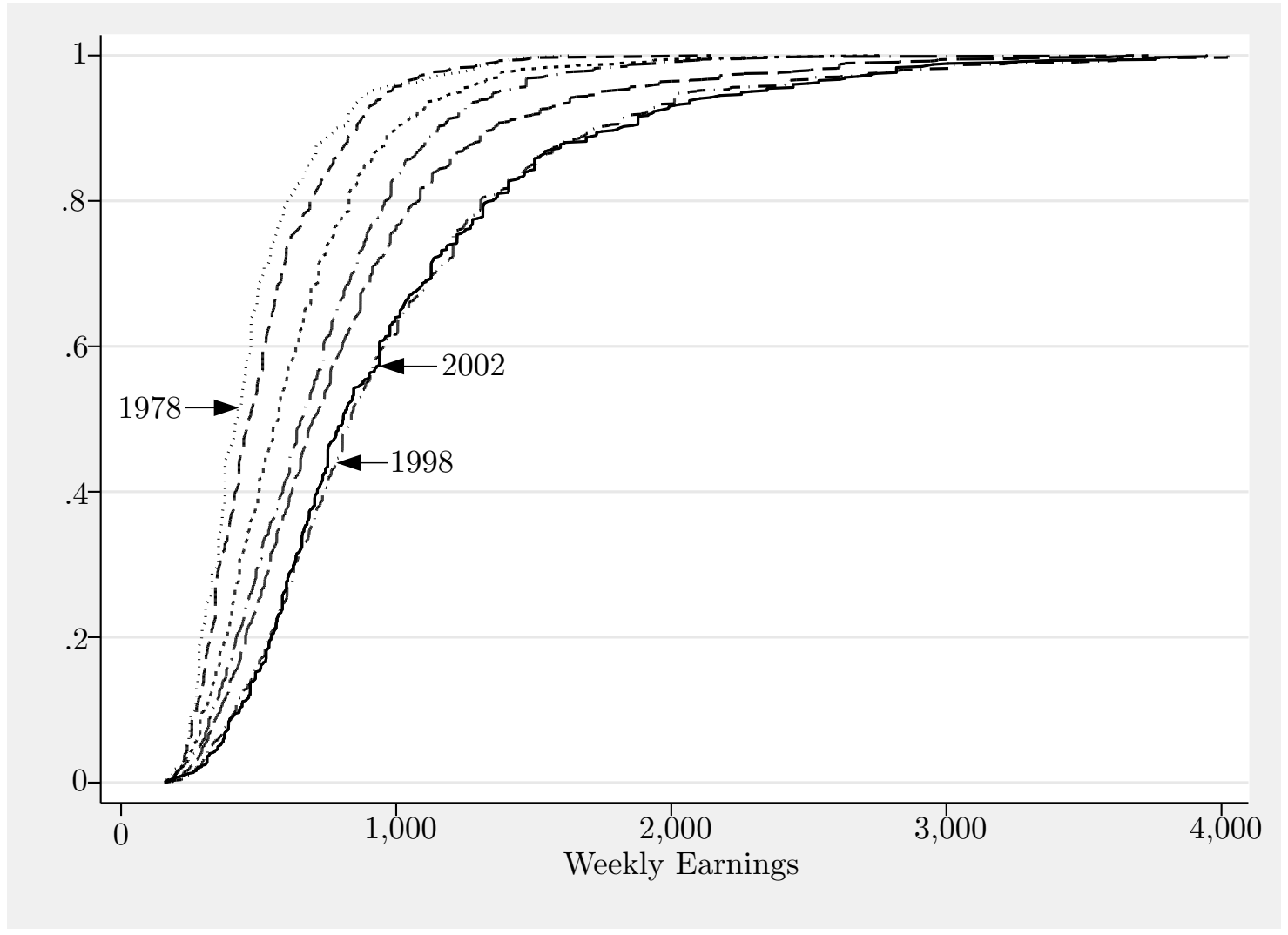

Figure 2: Empirical Earnings Distributions: White Males, 1978-2002

Note: The most left CDF is drawn for June 1978, and then every 4 years. The CDFs move from left to right in chronological order. The distribution appears to have converged by the end of the sample, as evidenced by the the fact that for 1998 and 2002, the CDFs lie directly on top of each other. A formal statistical test (Kolmogorov-Smirnov) does not reject the hypothesis that the CDFs for 1998 and 2002 are the same, while it does reject the hypotheses that any other pair are the same. 


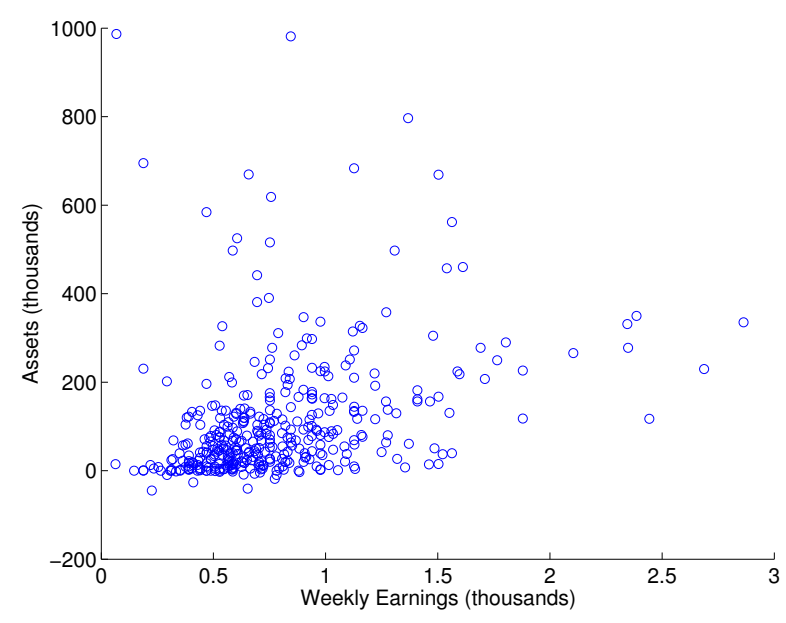

(a) High School

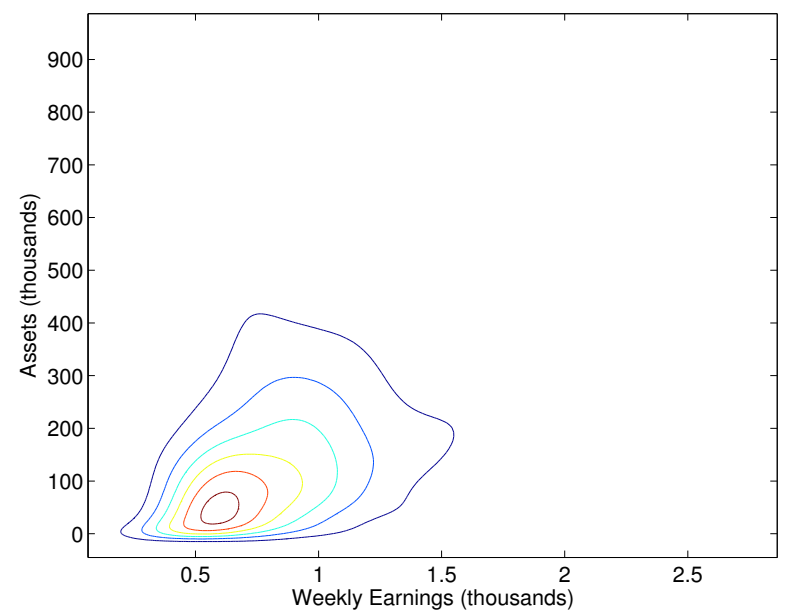

(c) High School

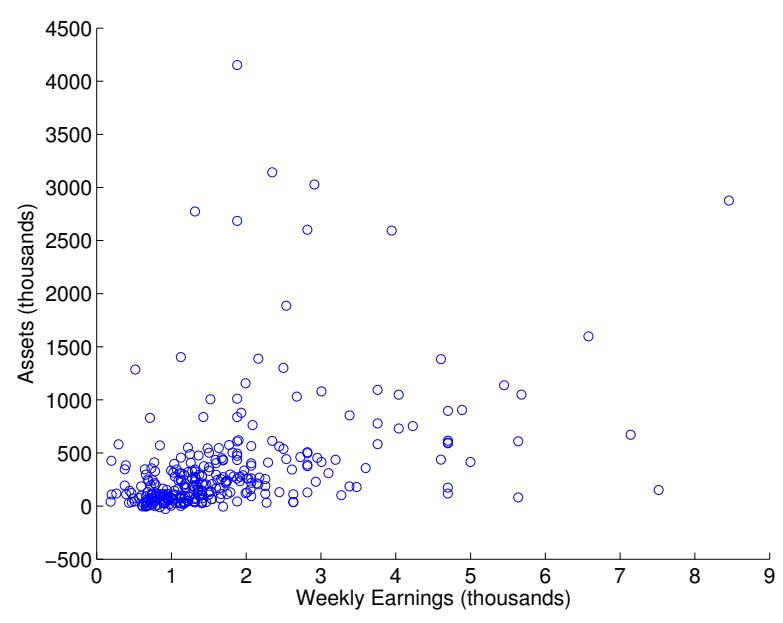

(b) College

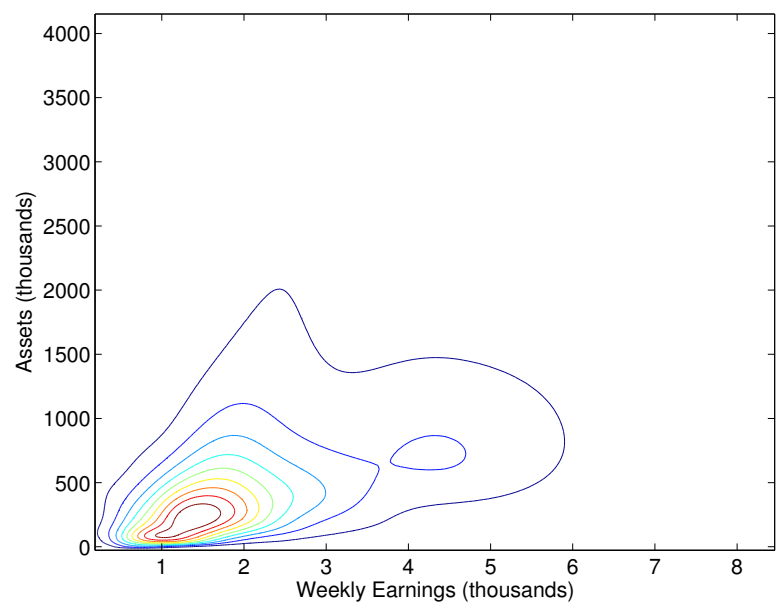

(d) College

Figure 3: Joint distribution of Earnings and Assets

Note: The data are for white males in the NLSY79, week 1269 (Summer of 2002). The top panels plot assets against wages. The bottom two panels are kernel density estimates for the joint distribution. The kernel is applied to transformed data, where assets and wages are transformed according to $\mathcal{A}=\log (a-\underline{a}+1)$ and $\mathcal{W}=\log (w+1)$. The figures plot the kernel density estimates after the data have been transformed back to levels. The contour lines for the joint density are drawn at equally spaced heights of the PDF. This implies that where the lines are close together, the slope of the density is very steep, and conversely, the slop is flatter the further apart are the contour lines. 


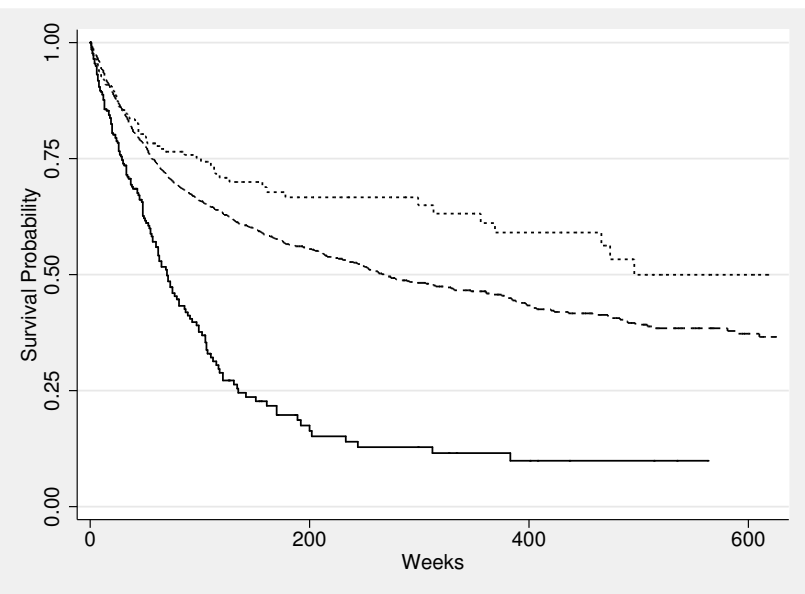

(a) Job Duration by Wages, High School

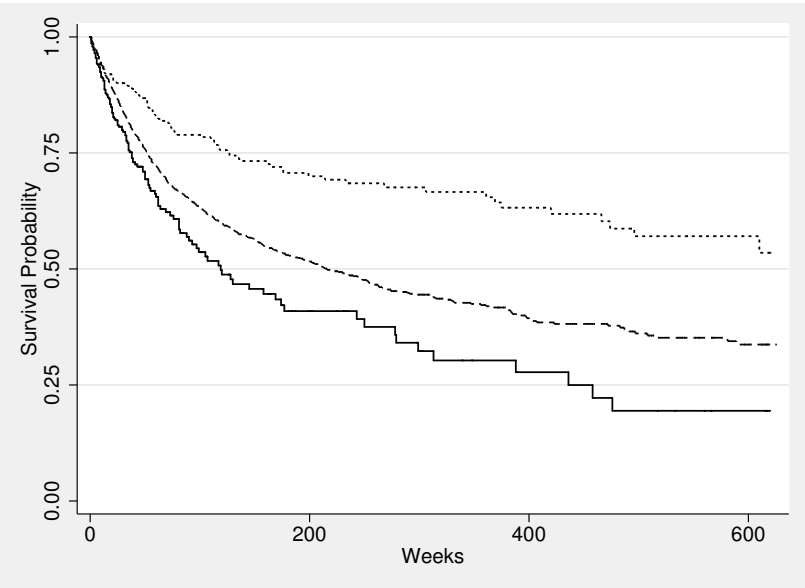

(c) Job Duration by Assets, High School

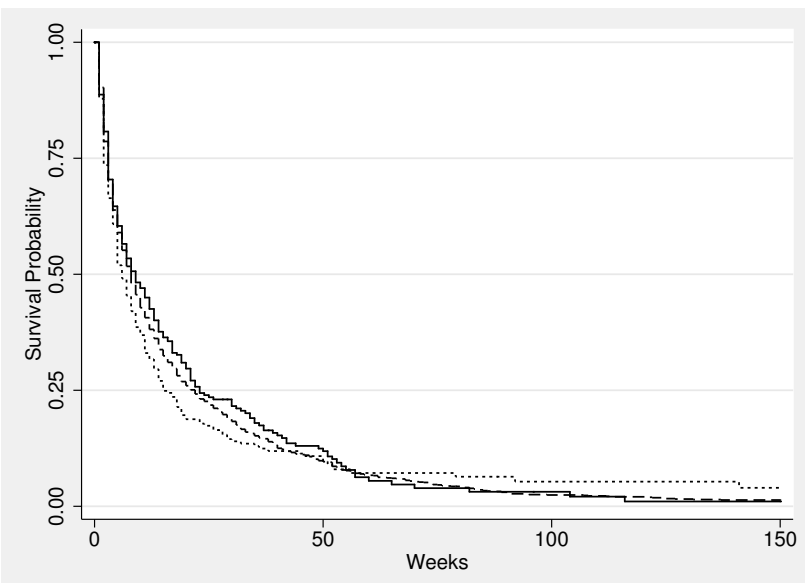

(e) Unemployment Duration by Assets, High School

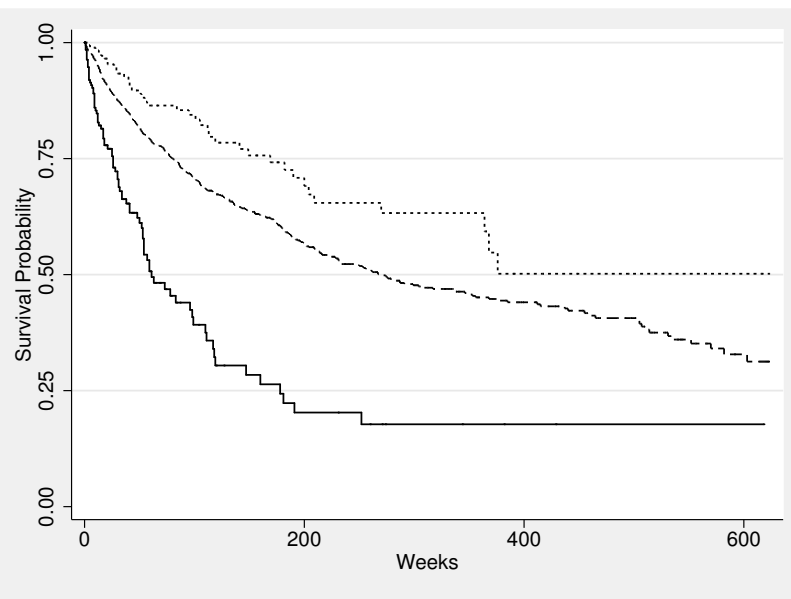

(b) Job Duration by Wages, College

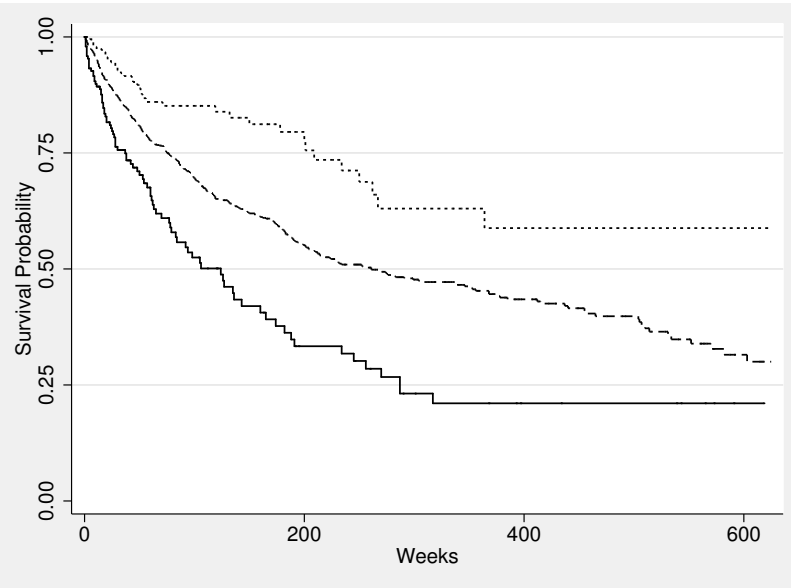

(d) Job Duration by Assets, College

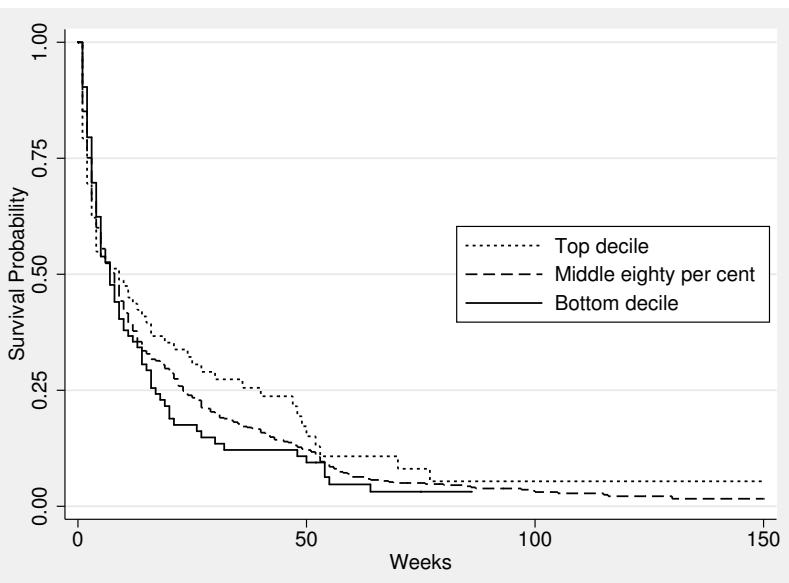

(f) Unemployment Duration by Assets, College

Figure 4: Job and Unemployment Durations

Note: All transitions are to jobs. For the employment spells the duration is time on current job before leaving for another job; exits to unemployment are treated as censored. This is consistent with estimation of a competing hazards model, where the events job offer and job destruction are independent. 


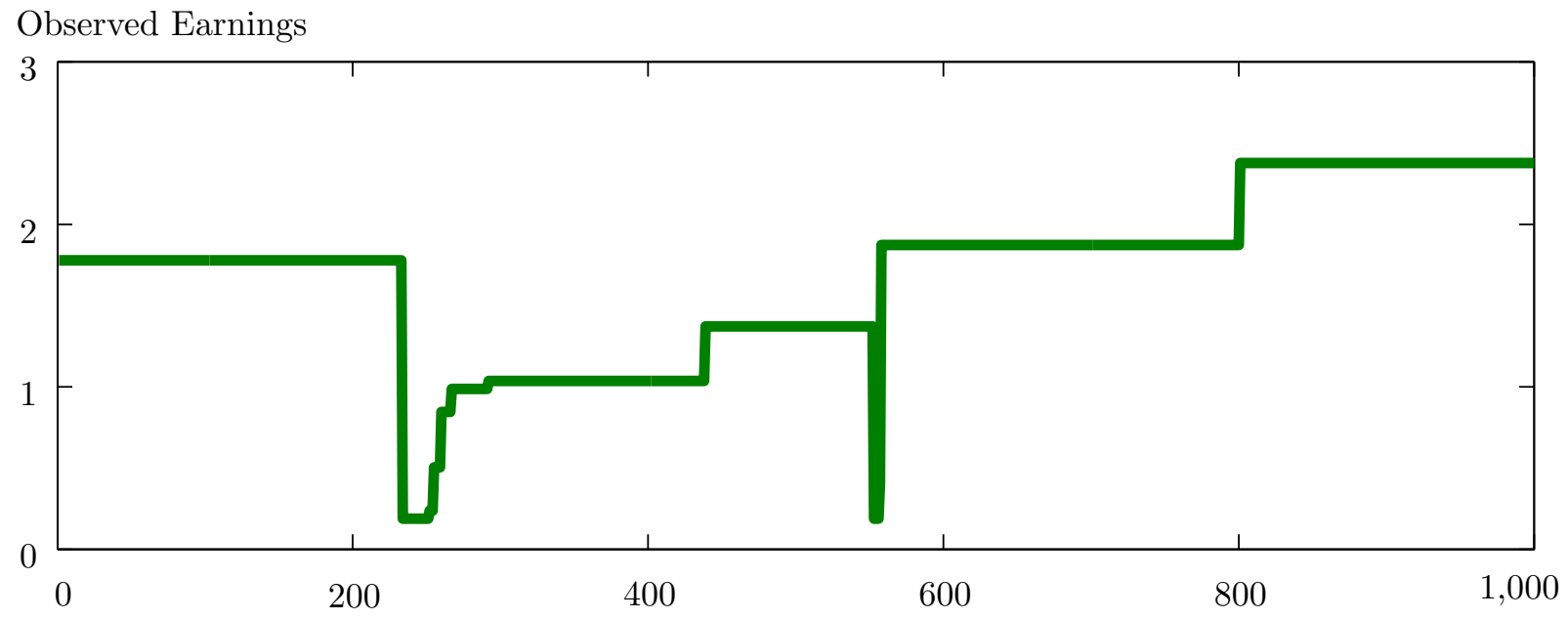

Predicted Assets

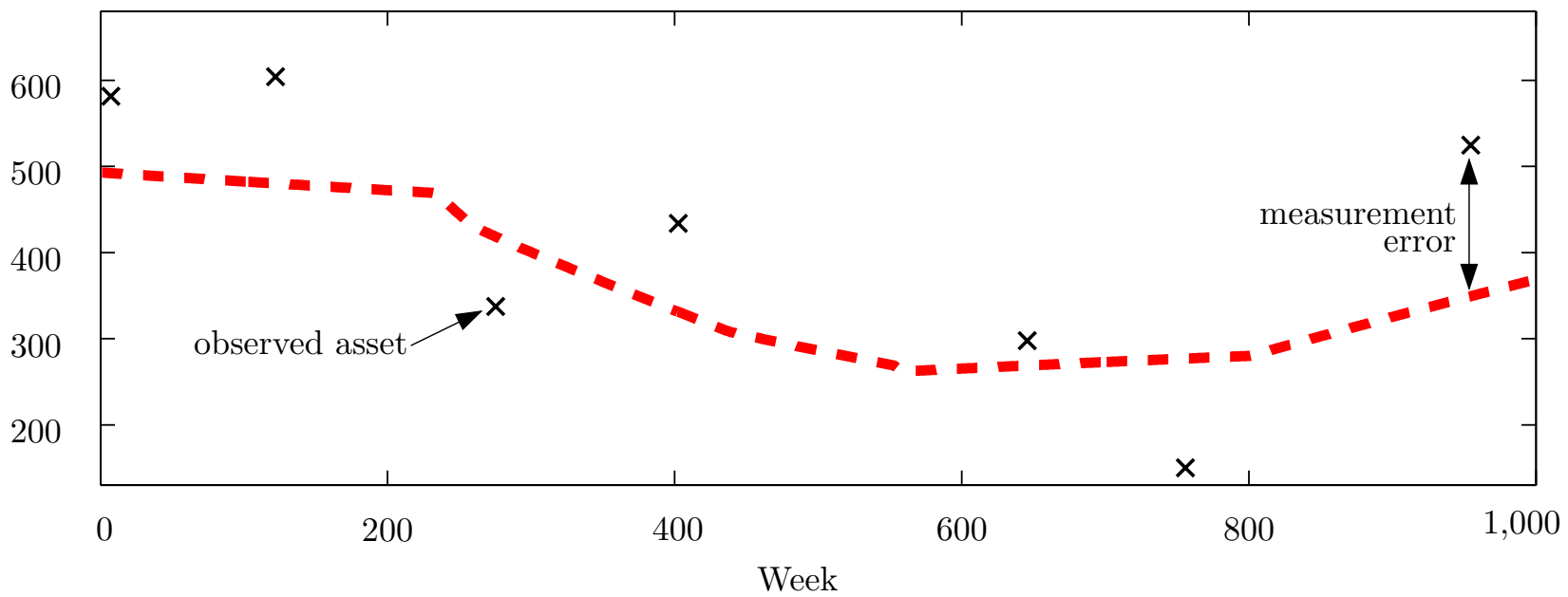

Figure 5: Likelihood contribution of a typical individual

Note: The contribution for one simulation $r$ comprises the probability of observing the pattern of job spells and wages depicted in the top panel (conditional on the simulated asset path in the bottom panel) and the contribution of the measurement error in assets depicted in the bottom panel. 


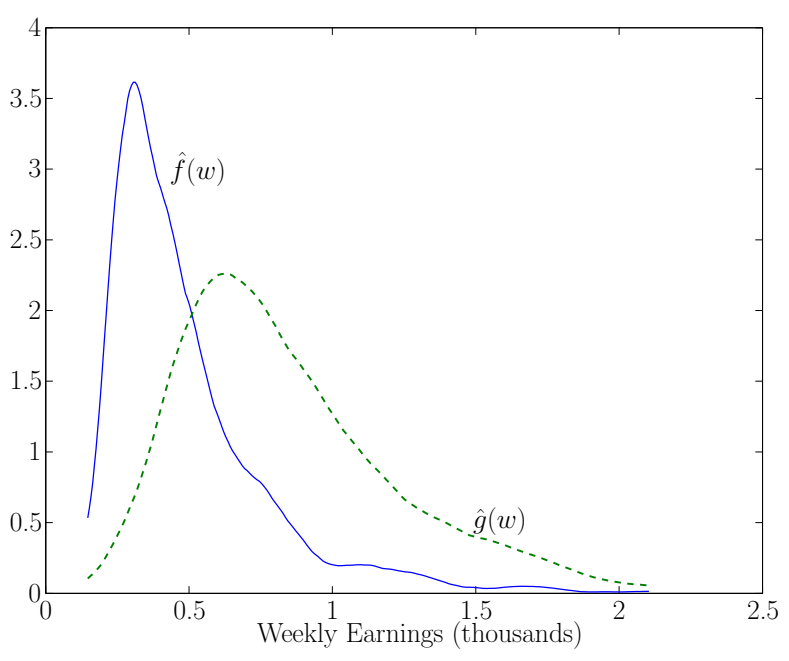

(a) High School, pdf

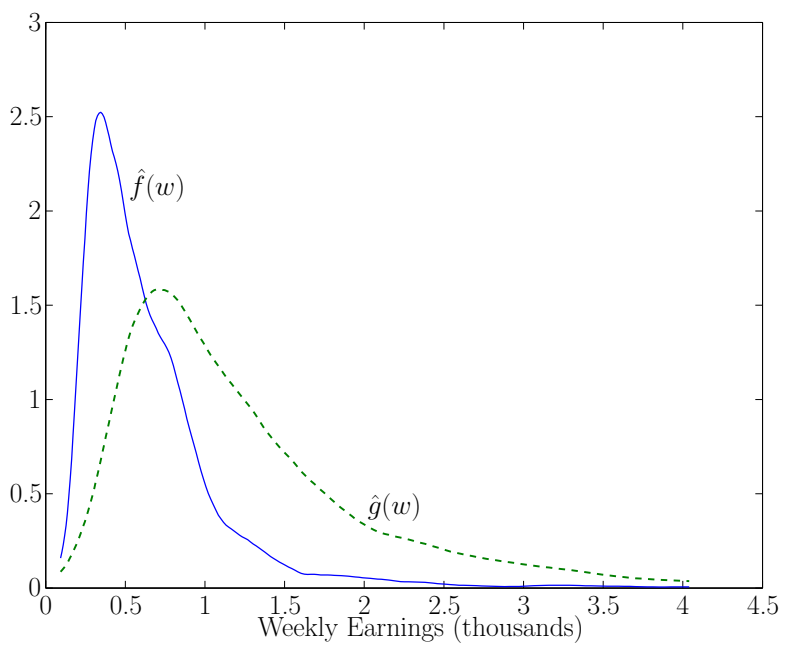

(c) College, pdf

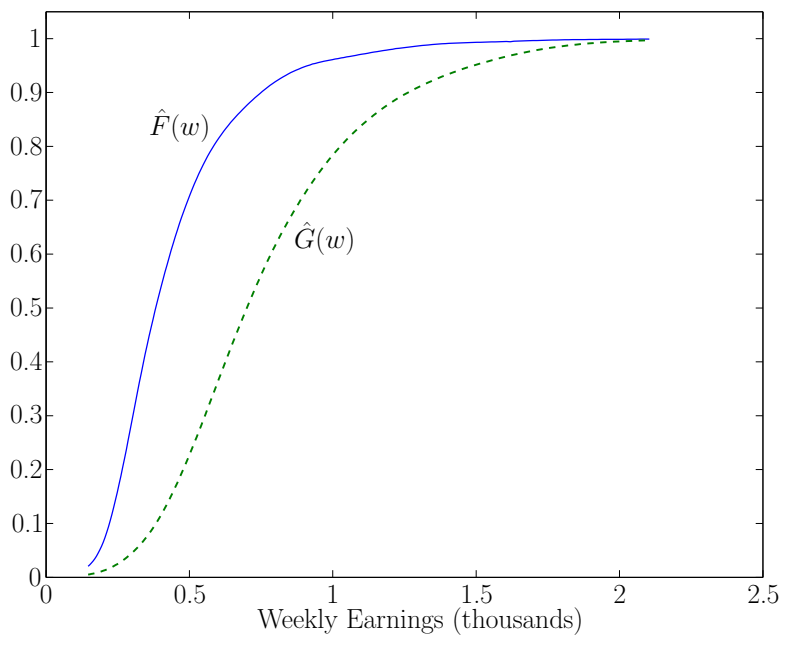

(b) High School, cdf

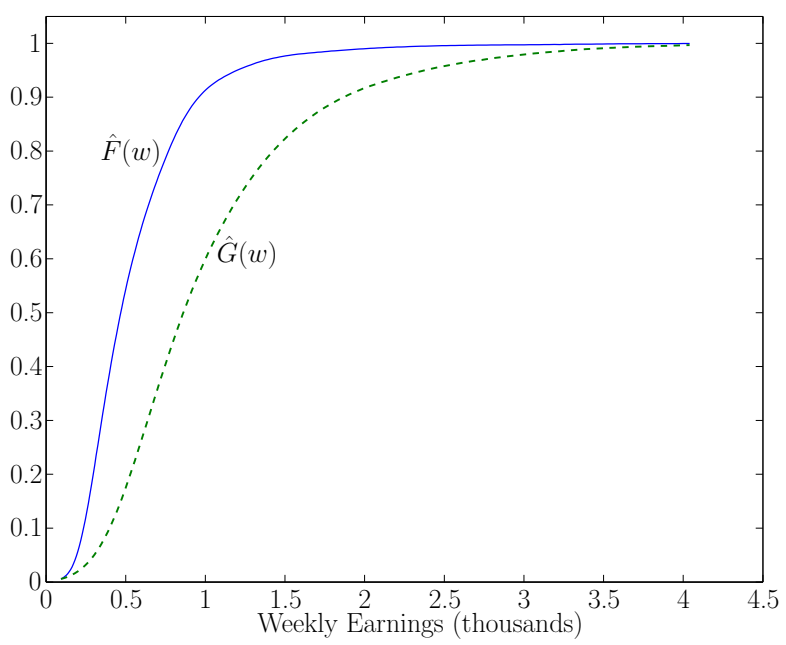

(d) College, cdf

\section{Figure 6: Estimated Offered and Accepted Wage Distributions}

Note: These are non-parametric estimates of the empirical offered and accepted wage densities: $\hat{f}(w)$ and $\hat{g}(w)$. Epanechnikov (quadratic) kernel, with the bandwidth selected by rule of thumb (Silverman 1986). The distribution functions are estimated as $\hat{F}(w)=\int_{\underline{w}}^{w} \hat{f}(x) d x$ and $\hat{G}(w)=\int_{\underline{w}}^{w} \hat{g}(x) d x$. The offer distribution is estimated from the distribution of wages accepted out of unemployment. This is a consistent estimate since all offers received when unemployed are accepted. For the preliminary results presented in the current version I use this offer distribution and a two stage estimation strategy. For efficient estimates, this is to be replaced by equations (19) and (20) in the likelihood function. 


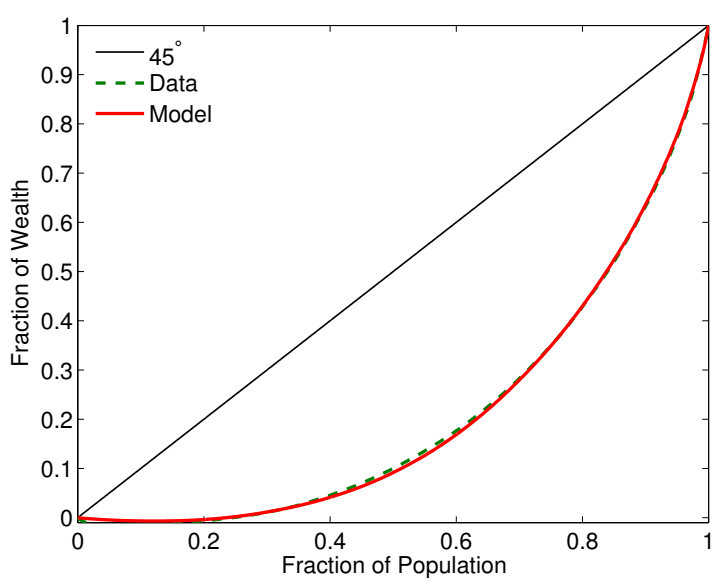

(a) High School

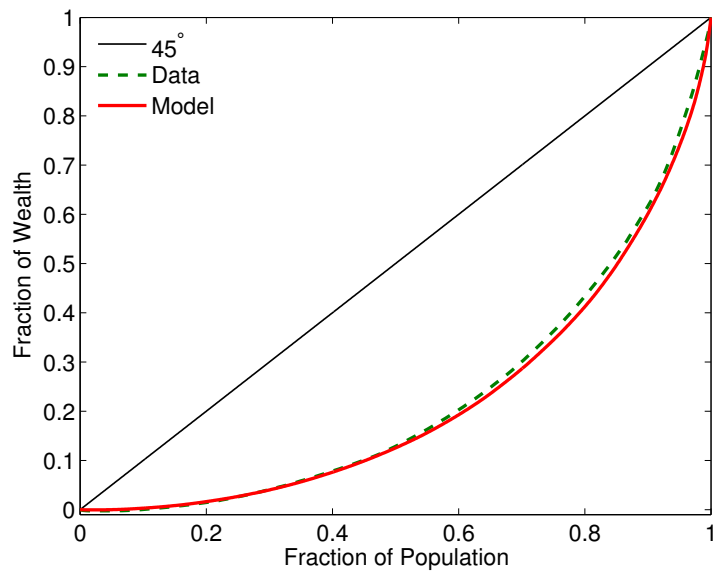

(b) College

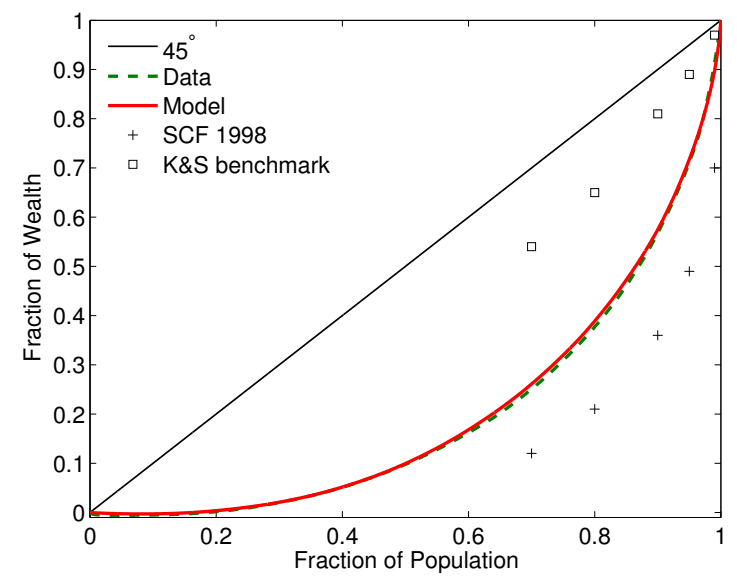

(c) Pooled Education

Figure 7: Lorenz Curves for Wealth: Model and Data

Note: Based on preliminary estimates. The fit to the Lorenz curves for both the individual education groups, and the pooled data is very good; the curves for the model and the data are almost indistinguishable. The + marks in the bottom panel mark the Lorenz coordinates calculated for the entire US economy based on the Survey of Consumer Finances 1998. The $\square$ marks in the same panel mark the Lorenz coordinates for the benchmark model (homogeneous discount rates) in Krusell and Smith (1998); both are taken from Table 1 of Krusell and Smith. The level of inequality within the two education groups is quite high, and it is even higher when they are pooled. That it is less than the degree in the entire US economy is due to the focus on a homogeneous group: white males born between 1957 and 1965. Adding in more heterogeneous groups will certainly increase the overall level of inequality. Formal statistical tests for the equality of the Lorenz curves can be undertaken using the procedures developed in Davidson and Duclos (2000). I defer the formal testing until the final estimates are available. 
Table 1: Summary Statistics.

\begin{tabular}{|c|c|c|c|c|c|c|c|}
\hline \multirow{3}{*}{ Weekly Earnings } & \multirow[b]{3}{*}{ mean } & \multicolumn{3}{|c|}{ Raw data } & \multicolumn{3}{|c|}{ Top and Bottom $0.5 \%$ trimmed } \\
\hline & & \multicolumn{2}{|c|}{ Pooled High School } & \multirow{2}{*}{$\begin{array}{r}\text { College } \\
1,802\end{array}$} & \multicolumn{2}{|c|}{ Pooled High School } & \multirow{2}{*}{$\begin{array}{r}\text { College } \\
1,718\end{array}$} \\
\hline & & 1,258 & 834 & & 1,191 & 788 & \\
\hline & median & 902 & 706 & 1,353 & 902 & 704 & 1,353 \\
\hline & s.d. & 1,225 & 670 & 1,526 & 981 & 399 & 1,259 \\
\hline & c.v. & 0.974 & 0.803 & 0.847 & 0.824 & 0.506 & 0.733 \\
\hline \multirow[t]{5}{*}{ Assets } & mean & 228,890 & 112,615 & 376,006 & 202,780 & 112,174 & 357,951 \\
\hline & median & 104,554 & 67,618 & 187,366 & 104,847 & 67,667 & 194,782 \\
\hline & s.d. & 490,824 & 243,213 & 657,944 & 303,782 & 144,132 & 534,625 \\
\hline & c.v. & 2.144 & 2.160 & 1.750 & 1.498 & 1.285 & 1.494 \\
\hline & $\mathrm{N}$ & 743 & 415 & 328 & 696 & 390 & 303 \\
\hline
\end{tabular}

Source: NLSY79. The sample is White Males, aged 37-45 in 2002. Wages are calculated as hourly earnings times weekly hours, conditional on hours being grater than or equal to 35 . The data correspond to week 1269 , which is in the summer of 2002.

Table 2: Model Parameters

\begin{tabular}{|c|c|c|c|}
\hline \multicolumn{4}{|c|}{ Fixed Parameters } \\
\hline & interest rate (annual) & \multicolumn{2}{|c|}{0.03} \\
\hline & rate of time preference (annual) & \multicolumn{2}{|c|}{0.05} \\
\hline & scale of search costs & \multicolumn{2}{|c|}{0.10} \\
\hline \multicolumn{4}{|c|}{ Estimated Parameters (Indirect Inference) ${ }^{a}$} \\
\hline & & High School & College \\
\hline$\gamma$ & coefficient of relative risk aversion & 1.441 & 2.346 \\
\hline$\zeta$ & minimum weekly consumption $^{b}$ & 0.137 & 0.178 \\
\hline$\eta$ & search costs (elasticity: $1+1 / \eta$ ) & 1.512 & 1.293 \\
\hline$\lambda$ & job contact rate (weekly) & 0.0527 & 0.0110 \\
\hline$\delta$ & job destruction rate (weekly) & 0.00354 & 0.00192 \\
\hline
\end{tabular}

${ }^{a}$ Preliminary Estimates. Standard errors not available for current draft.

${ }^{b}$ Measured in thousands of 2001 dollars. 
Table 3: Aggregate Implications Of Estimates

\begin{tabular}{ccccccc}
\hline & \multicolumn{2}{c}{ High School } & \multicolumn{2}{c}{ College } & \multicolumn{2}{c}{ Pooled } \\
& Data & Model & Data & Model & Data & Model \\
\hline \multicolumn{2}{l}{ Labor Market Characteristics } \\
\multicolumn{2}{l}{ Median Unemployment Duration } \\
Assets below median & 8 & 2 & 6 & 2 & 8 & 2 \\
Assets above median & 6 & 3 & 7 & 3 & 6 & 3 \\
\hline Median Job Duration & & & & & & \\
Assets below median & 25 & 15 & 38 & 12 & 27 & 14 \\
Assets above median & 32 & 16 & 47 & 17 & 35 & 16 \\
\hline
\end{tabular}

Lorenz Co-ordinates

\begin{tabular}{lllllll}
\hline Earnings & & & & & & \\
Top 1 percent & 0.0262 & 0.0214 & 0.0454 & 0.0266 & 0.0440 & 0.0315 \\
Top 5 percent & 0.1112 & 0.0921 & 0.1420 & 0.1053 & 0.1675 & 0.1184 \\
Top 10 percent & 0.1964 & 0.1694 & 0.2501 & 0.1843 & 0.2706 & 0.2044 \\
Top 20 percent & 0.3385 & 0.3055 & 0.4086 & 0.3179 & 0.4224 & 0.3515 \\
Top 30 percent & 0.4611 & 0.4274 & 0.5334 & 0.4370 & 0.5420 & 0.4748 \\
Bottom 25 percent & 0.1364 & 0.1473 & 0.1053 & 0.1443 & 0.1056 & 0.1272 \\
Wealth & & & & & & \\
Top 1 percent & 0.0605 & 0.0601 & 0.0811 & 0.0871 & 0.0865 & 0.1030 \\
Top 5 percent & 0.2321 & 0.2229 & 0.2259 & 0.2611 & 0.2882 & 0.2827 \\
Top 10 percent & 0.3659 & 0.3640 & 0.3845 & 0.3989 & 0.4319 & 0.4252 \\
Top 20 percent & 0.5688 & 0.5702 & 0.5680 & 0.5878 & 0.6224 & 0.6112 \\
Top 30 percent & 0.7147 & 0.7203 & 0.7012 & 0.7140 & 0.7487 & 0.7389 \\
Bottom 25 percent & 0.0008 & 0.0021 & 0.0271 & 0.0268 & 0.0091 & 0.0109 \\
\hline
\end{tabular}

\begin{tabular}{ccccccc} 
Autocorrelations $^{a}$ & & & & & & \\
\hline $\operatorname{Corr}\left(w_{t}, w_{t-1}\right)$ & 0.5179 & 0.5331 & 0.5262 & 0.7479 & 0.4555 & 0.5917 \\
$\operatorname{Corr}\left(a_{t}, a_{t-1}\right)$ & 0.6729 & 0.7819 & 0.7164 & 0.9468 & 0.7060 & 0.8230 \\
\hline
\end{tabular}

\footnotetext{
${ }^{a}$ The subscript $t-1$ refers to a one interview lag.
} 


\section{A Equation (5) as the Limit of the Discrete Time Bellman Equa- tions}

Consider a discrete time model where the length of a time period is $\Delta t$. The continuous time Bellman equation (5) can be derived as the limit where $\Delta t$ goes to zero.

$$
\begin{aligned}
& W(a, w, t)=\max _{0 \leq c \leq a-\underline{a}, 0 \leq s}\{(u(c(a, w, t))-e(s(a, w, t))) \Delta t \\
&+\frac{1}{1+\rho \Delta t}( \lambda s \Delta t \int \max \{W(a+\Delta a, x, t+\Delta t), W(a+\Delta a, w, t+\Delta t)\} d F(x) \\
&+\delta \Delta t U(a+\Delta a, t+\Delta t)+[1-\lambda s \Delta t-\delta \Delta t] W(a+\Delta a, w, t+\Delta t) \\
&+o(\Delta t))\},
\end{aligned}
$$

where $o(\Delta t)$ are terms that go to zero faster than $\Delta t$ (for example, the probability of a job offer and a job destruction in the same period). Multiply by $(1+\rho \Delta t)$ and rearrange,

$$
\begin{aligned}
\rho \Delta t W(a, w, t)=\max _{0 \leq c \leq a-\underline{a}, 0 \leq s} & \{(1-\rho \Delta t)(u(c(a, w, t))-e(s(a, w, t))) \Delta t \\
& +\lambda s \Delta t \int \max \{W(a+\Delta a, x, t+\Delta t)-W(a+\Delta a, w, t+\Delta t), 0\} d F(x) \\
+ & \delta \Delta t[U(a+\Delta a, t+\Delta t)-W(a+\Delta a, w, t+\Delta t)] \\
+ & {[W(a+\Delta a, w, t+\Delta t)-W(a, w, t)]+o(\Delta t)\} . }
\end{aligned}
$$

Dividing by $\Delta t$ and taking the limit as $\Delta t$ goes to zero,

$$
\begin{aligned}
\rho W(a, w, t)=\max _{0 \leq c \leq a-\underline{a}, 0 \leq s} & \{u(c(a, w, t))-e(s(a, w, t)) \\
& +\lambda s \int \max \{W(a, x, t)-W(a, w, t), 0\} d F(x) \\
+ & \left.\delta[U(a, t)-W(a, w, t)]+W_{a}(a, w, t)[r a+w-c]\right\},
\end{aligned}
$$

where the last line follows from $\lim _{\Delta t \rightarrow 0}[W(a+\Delta a, w, t+\Delta t)-W(a, w, t)] / \Delta t=d W(a, w, t) / d t=$ $W_{a}(a, w, t) d a / d t$, and $\lim _{\Delta t \rightarrow 0} o(\Delta t) / \Delta t=0 .{ }^{27}$

${ }^{27}$ An alternative derivation of equation (5) starts with the discrete time Bellman equation

$$
W(a, w, t)=\max _{c, s}\left\{(u(c(a, w, t))-e(s(a, w, t))) \Delta t+(1+\rho \Delta t)^{-1} \mathrm{E}\left[W\left(a^{\prime}, w^{\prime}, t\right) \mid a, w, c, s\right]\right\} .
$$

Multiply by $(1+\rho \Delta t)$, divide by $\Delta t$ and take the limit as $\Delta t$ goes to zero to obtain

$$
\rho W(a, w, t)=\max _{c, s}\left\{(u(c(a, w, t))-e(s(a, w, t)))+\frac{1}{d t} \mathrm{E}[d W]\right\} .
$$

In the current context, $\mathrm{E}[d W]=W_{a}(a, w)[r a+w-c] d t+s \lambda d t \int \max \{W(a, x)-W(a, w), 0\} d F(x)+\delta d t[U(a)-$ $W(a, w)]$ (See Kushner (1967, p. 20) or Merton (1971) for a derivation of the appropriate differential generating function for a Poisson process). 


\section{B Additional IID Income Uncertainty}

This section explores the implications of a more general version of the model presented in the body of the paper in which uncertainty in non-labor income is included, specifically the addition of a Brownian motion component to the budget constraint. In general the variance of this component may be a function of the current state, so in what follows $\sigma$ may be read as $\sigma(a, w)$. Indeed, $\sigma(a, \underline{w})=0$ is a necessary condition to guarantee positive consumption when unemployed.

The addition of an additional Brownian motion income process can be expressed compactly in the asset accumulation equation as:

$$
d a=[r a+w-c] d t+\sigma d z .
$$

The corresponding value functions can be written as:

$$
\begin{aligned}
& \rho U(a)=\max _{0 \leq c \leq a+\underline{a}, 0 \leq s}\left\{u(c)-e(s)+U_{a}(a)[r a+b-c]+\frac{\sigma^{2}}{2} U_{a a}(a)\right. \\
&+\left.\lambda s \int \max \{W(a, x)-U(a), 0\} d F(x)\right\} . \\
& \rho W(a, w)=\max _{0 \leq c \leq a+\underline{a}, 0 \leq s}\left\{u(c)-e(s)+W_{a}(a, w)[r a+w-c]+\frac{\sigma^{2}}{2} W_{a a}(a, w)\right. \\
&\left.+\lambda s \int \max \{W(a, x)-W(a, w), 0\} d F(x)+\delta[U(a)-W(a, w)]\right\} .
\end{aligned}
$$

Note that the first order conditions are unchanged with the addition of the diffusion term, but the value function will be lower due to the terms $\frac{1}{2} \sigma^{2} U_{a a}(a)$ and $\frac{1}{2} \sigma^{2} W_{a a}(a, w)$.

The differential equation characterizing consumption, analogous to equation (11), has an additional precautionary term that is sensitive to the variance of the iid random shock $\left(\sigma^{2}\right)$ :

$$
\frac{\dot{c}}{c}=\frac{1}{\gamma(c)}\left(r-\rho-\lambda s\left(\bar{F}(w)-\int_{w}^{\bar{w}} \frac{u^{\prime}(\hat{c})}{u^{\prime}(c)} d F(x)\right)+\delta\left(\frac{u^{\prime}(\underline{c})}{u^{\prime}(c)}-1\right)\right)-\frac{\sigma^{2}}{2}\left(\frac{u^{\prime \prime \prime}(c)}{u^{\prime \prime}(c)} \frac{c_{a}}{c}-\frac{c_{a a}}{c}\right),
$$

where $\gamma(c)$ is the coefficient of relative risk aversion. For unambiguous additional precaution we require that the third derivative of the utility function $u^{\prime \prime \prime}(c)$ be positive (the consumption function is concave so $c_{a a}$ is negative). The term

$$
\frac{\sigma^{2}}{2}\left(\frac{u^{\prime \prime \prime}(c)}{u^{\prime \prime}(c)} \frac{c_{a}}{c}-\frac{c_{a a}}{c}\right)
$$

is exactly the Kimball (1990) definition of the degree of prudence.

\section{Derivations and Proofs}

\section{C.1 The Reservation Wage}

Proof of Proposition 2: Since for all asset level $a$, the value of being employed $W(a, w)$ is increasing in $w$, an employed worker always accepts any wage higher than his current wage. Since at each asset level $a$, the value of being unemployed $U(a)$ is independent of $w$, then for any asset level $a$ there is a unique reservation wage $R(a)$ above which the value of employment is higher than the value of unemployment. This reservation wage is the unique solution to

$$
W(a, R(a))=U(a)
$$


Expanding this relationship gives

$$
\begin{aligned}
\rho U(a)= & u(c(a, b))-e(s(a, b))+U_{a}(a)[r a+b-c(a, b)]+\lambda s(a, b) \int_{R(a)}^{\bar{w}}[W(a, x)-U(a)] d F(x) \\
= & u(c(a, R(a)))-e(s(a, R(a)))+W_{a}(a, R(a))[r a+R(a)-c(a, R(a))] \\
& \quad+\lambda s(a, R(a)) \int_{R(a)}^{\bar{w}}[W(a, x)-W(a, R(a))] d F(x)+\delta[U(a)-W(a, R(a))] \\
= & \rho W(a, w)
\end{aligned}
$$

Substituting $W(a, R(a))=U(a)$ using the reservation wage property, and substituting $u^{\prime}(c)=U_{a}=W_{a}$ using the first order conditions for consumption we have

$$
\begin{aligned}
u(c(a, b))-e(s(a, b))-u(c(a, R(a)))+e(s(a, R(a))) & \\
+u^{\prime}(c(a, b))[r a & +b-c(a, b)]-u^{\prime}(c(a, R(a)))[r a+R(a)-c(a, R(a))] \\
+ & {[\lambda s(a, b)-\lambda s(a, R(a))] \int_{R(a)}^{\bar{w}}[W(a, x)-W(a, R(a))] d F(x)=0 . }
\end{aligned}
$$

We can directly verify that the solution occurs at

$$
s(a, R(a))=s(a, b), \quad c(a, R(a))=c(a, b), \quad \text { and } \quad R(a)=b .
$$

The reservation wage is independent of assets and equal to the unemployment benefits.

\section{C.2 Properties of Optimal Consumption and Search Effort}

PROOF OF PROPOSITION 3: Implicit differentiation of the first order conditions produces:

$$
\begin{aligned}
c_{a}(a, w) & =\frac{W_{a a}(a, w)}{u_{c c}}, \quad c_{a}(a, b)=\frac{U_{a a}(a, b)}{u_{c c}}, \\
c_{w}(a, w) & =\frac{W_{a w}(a, w)}{u_{c c}}, \quad c_{w}(a, b)=\frac{U_{a w}(a, b)}{u_{c c}}, \\
s_{w}(a, w) & =\frac{\lambda W_{w}(a, w) \bar{F}(w)}{u_{s s}} \cdot \quad s_{w}(a, b)=\frac{\lambda W_{w}(a, b) \bar{F}(b)}{u_{s s}} \\
s_{a}(a, w) & =-\frac{\lambda \int_{w}^{\bar{w}}\left[W_{a}(a, x)-W_{a}(a, w)\right] d F(x)}{u_{s s}} \\
& =-\frac{\lambda \int_{w}^{\bar{w}}\left[u_{c}(c(a, x), s(a, x))-u_{c}(c(a, w), s(a, w))\right] d F(x)}{u_{s s}} \\
s_{a}(a, b) & =-\frac{\lambda \int_{b}^{\bar{w}}\left[W_{a}(a, x)-U_{a}(a)\right] d F(x)}{u_{s s}} \\
& =-\frac{\lambda \int_{b}^{\bar{w}}\left[u_{c}(c(a, x), s(a, x))-u_{c}(c(a, b), s(a, b))\right] d F(x)}{u_{s s}},
\end{aligned}
$$

where I make use of the notation $\bar{F}(x) \equiv[1-F(x)]$. These conditions imply that consumption is increasing with assets if and only if $W_{a a}$ and $U_{a a}$ are negative; there must be a diminishing marginal value of wealth. A sufficient condition for this is that $W$ and $U$ are globally strictly concave in assets. This is satisfied in the current environment, and follows directly from the assumption that preferences and the search technology do not depend on whether the worker is employed or unemployed.

Similarly, search effort is decreasing with assets as long as $u_{c}$ is decreasing in $w$. The denominator is negative $\left(u_{s s}<0\right.$, and $W(a, w)$ is increasing in $\left.w\right)$, and numerator is negative as long as $w^{\prime}>w$ implies that $u_{c}\left(c\left(a, w^{\prime}\right), s\left(a, w^{\prime}\right)\right)<u_{c}(c(a, w), s(a, w))$. 


\section{C.3 Optimal Search Effort}

DERIVATION OF EQUATION 10: Given the reservation wage strategy, and the fact that employed workers accept any wage higher than their current wage, equation (7) can be rewritten as

$$
\begin{aligned}
e^{\prime}(s) & =\lambda \int \max \{W(a, x)-W(a, w), 0\} d F(x) \\
& =\lambda \int_{w}^{\bar{w}}[W(a, x)-W(a, w)] d F(x) \\
& =\lambda\left[\int_{w}^{\bar{w}} W(a, x) d F(x)-\bar{F}(w) W(a, w)\right] \\
& =\lambda \int_{w}^{\bar{w}} W_{w}(a, x) \bar{F}(x) d x \\
& =\lambda \int_{w}^{\bar{w}} \frac{W_{a}+W_{a w}[r a+x-c]}{\rho+\delta+\lambda s \bar{F}(x)} \bar{F}(x) d x \\
& =\lambda \int_{w}^{\bar{w}} \frac{u^{\prime}(c)+\left[u^{\prime \prime}(c) c_{w}\right][r a+x-c]}{\rho+\delta+\lambda s \bar{F}(x)} \bar{F}(x) d x
\end{aligned}
$$

where the second line follows from $W(a, w)$ being increasing in $w$, the third line follows directly, the fourth line uses the fact that integration by parts implies that

$$
\begin{aligned}
\int_{w}^{\bar{w}} W_{w}(a, x) \bar{F}(x) d x & =\left.W(a, x) \bar{F}(x)\right|_{w} ^{\bar{w}}-\int_{w}^{\bar{w}} W(a, x)(-f(x)) d x \\
& =\int_{w}^{\bar{w}} W(a, x) d F(x)-\bar{F}(w) W(a, w),
\end{aligned}
$$

the fifth line substitutes for

$$
W_{w}=\frac{W_{a}+W_{a w}[r a+w-c]}{\rho+\delta+\lambda s \bar{F}(w)},
$$

and the final line uses the first order condition for consumption, to substitute in $W_{a}(a, w)=u^{\prime}(c)$ and $W_{a w}=u^{\prime \prime}(c) c_{w}(a, w)$.

\section{C.4 Optimal Consumption Growth}

Derivation of Equation (11): Applying the envelope theorem to the value of employment, we can write:

$$
\begin{aligned}
\rho W_{a}(a, w)= & W_{a a}(a, w)[r a+w-c]+r W_{a}(a, w) \\
& \quad+\lambda s \int_{w}^{\bar{w}} W_{a}(a, x) d F(x)-\lambda s \bar{F}(w) W_{a}(a, w)+\delta\left[U_{a}(a)-W_{a}(a, w)\right]
\end{aligned}
$$

or equivalently,

$$
\begin{aligned}
W_{a a}(a, w)[r a+w-c]=[\rho-r & +\delta+\lambda s \bar{F}(w)] W_{a}(a, w) \\
& -\delta U_{a}(a)-\lambda s \int_{w}^{\bar{w}} W_{a}(a, x) d F(x)
\end{aligned}
$$

Recall that the state variables evolve according to

$$
\begin{aligned}
d a & =[r a+w-c] d t \\
d w & =\max \{\tilde{w}-w, 0\} d q_{\lambda s}+[\underline{w}-w] d q_{\delta},
\end{aligned}
$$


where $\tilde{w} \sim F(w)$. Proceed by totally differentiating $W_{a}$, making use of equations (35) and (36):

$$
\begin{aligned}
d W_{a}=W_{a a}[ & r a+w-c] d t \\
+ & {\left[W_{a}(a, \max \{\tilde{w}, w\})-W_{a}(a, w)\right] d q_{\lambda s}+\left[W_{a}(a, \underline{w})-W_{a}(a, w)\right] d q_{\delta} . }
\end{aligned}
$$

Now, multiply equation (34) by $d t$, add $\left[W_{a}(a, \max \{\tilde{w}, w\})-W_{a}(a, w)\right] d q_{\lambda s}+\left[W_{a}(a, \underline{w})-W_{a}(a, w)\right] d q_{\delta}$, and substitute using equation (37):

$$
\begin{aligned}
d W_{a}=[-r & +\rho+\delta+\lambda s \bar{F}(w)] W_{a}(a, w) d t-\lambda s \int_{w}^{\bar{w}} W_{a}(a, x) d F(x) d t-\delta W_{a}(a, \underline{w}) d t \\
& +\left[W_{a}(a, \max \{\tilde{w}, w\})-W_{a}(a, w)\right] d q_{\lambda s}+\left[W_{a}(a, \underline{w})-W_{a}(a, w)\right] d q_{\delta} .
\end{aligned}
$$

Concentrating on the time when neither an acceptable job offer is received, nor is the job destroyed $\left(d q_{\lambda s}=d q_{\delta}=0\right)$ we can obtain some incite into savings behavior at different wage levels. Making use of the first order condition $W_{a}(a, w)=u^{\prime}(c)$, and $d W_{a}(a, w)=u^{\prime \prime}(c) d c$, we can write:

$$
\begin{aligned}
-u^{\prime \prime}(c(a, w)) d c=[r- & \rho-\delta-\lambda s \bar{F}(w)] u^{\prime}(c(a, w)) d t \\
& +\lambda s \int_{w}^{\bar{w}} u^{\prime}(c(a, x)) d F(x) d t+\delta u^{\prime}(c(a, \underline{w})) d t, \quad d q_{\lambda s}=d q_{\delta}=0 .
\end{aligned}
$$

Rearranging we obtain an expression for consumption growth (alternatively asset growth) for a given wage $w$ as:

$$
\frac{\dot{c}}{c}=\frac{1}{\gamma(c)}\left(r-\rho-\lambda s\left(\bar{F}(w)-\int_{w}^{\bar{w}} \frac{u^{\prime}(\hat{c})}{u^{\prime}(c)} d F(x)\right)+\delta\left(\frac{u^{\prime}(\underline{c})}{u^{\prime}(c)}-1\right)\right),
$$

where $\dot{c}=d c / d t, \gamma(c)=-u^{\prime \prime}(c) c / u^{\prime}(c)$ is the coefficient of relative risk aversion, and I make use of the shorthand $\hat{c}=c(a, x)$, where $x$ is a dummy of integration, and $\underline{c}=c(a, b)$, with corresponding notation for $s$.

We can similarly derive the differential equation governing optimal consumption when unemployed as

$$
\frac{\dot{c}}{c}=\frac{1}{\gamma(c)}\left(r-\rho-\lambda s\left(1-\int_{b}^{\bar{w}} \frac{u^{\prime}(\hat{c})}{u^{\prime}(c)} d F(x)\right)\right)
$$

indeed equation (39) is nested by equation (38) since $\underline{w}=b$.

Optimal consumption and search are characterized by equations (33), (35), (36), (38), and the presentvalue budget constraint $\lim _{t \rightarrow \infty} \mathrm{e}^{-r t} a(t) \geq 0$ (a.s.).

\section{C.5 Impatience and Precaution Move in Opposite Directions as the Wage Increases}

Proof of Proposition 4: In equation (11), the term multiplying $\lambda s$ is decreasing in the wage, while the term multiplying $\delta$ is increasing in the wage:

$$
\begin{aligned}
\frac{\partial}{\partial w}\left(\bar{F}(w)-\int_{w}^{\bar{w}} \frac{u^{\prime}(c(a, x))}{u^{\prime}(c(a, w))} d F(x)\right) & =\int_{w}^{\bar{w}} \frac{u^{\prime}(c(a, x)) u^{\prime \prime}(c(a, w)) c_{w}(a, w)}{u^{\prime}(c(a, w))^{2}} d F(x)<0 \\
\frac{\partial}{\partial w}\left(\frac{u^{\prime}(c(a, \underline{w}))}{u^{\prime}(c(a, w))}-1\right) & =-\frac{u^{\prime}(c(a, \underline{w})) u^{\prime \prime}(c(a, w)) c_{w}(a, w)}{u^{\prime}(c(a, w))^{2}}>0 .
\end{aligned}
$$




\section{C.6 There is a Finite Upper Bound on Assets}

ProOF OF Proposition 5: Setting equation (11) equal to zero gives

$$
\begin{aligned}
0 & =r-\rho-\lambda s\left(\bar{F}(w)-\int_{w}^{\bar{w}} \frac{u^{\prime}(\hat{c})}{u^{\prime}(c)} d F(x)\right)+\delta\left(\frac{u^{\prime}(\underline{c})}{u^{\prime}(c)}-1\right), \\
\rho+\lambda s \bar{F}(w)+\delta-r & =\left(\lambda s \int_{w}^{\bar{w}} u^{\prime}(\hat{c}) d F(x)+\delta u^{\prime}(\underline{c})\right) \frac{1}{u^{\prime}(c)}, \\
u^{\prime}(c) & =\frac{\lambda s \int_{w}^{\bar{w}} u^{\prime}(\hat{c}) d F(x)+\delta u^{\prime}(\underline{c})}{\rho+\lambda s \bar{F}(w)+\delta-r}, \\
c & =\phi\left(\frac{\lambda s \int_{w}^{\bar{w}} u^{\prime}(\hat{c}) d F(x)+\delta u^{\prime}(\underline{c})}{\rho+\lambda s \bar{F}(w)+\delta-r}\right),
\end{aligned}
$$

where $\phi$ is the inverse function of the marginal utility of consumption $u^{\prime}(c)$. Setting $\dot{a} \equiv d a / d t=0$ (the asset accumulation equation) gives

$$
c=w+r a .
$$

For the existence of a stable saddle-path equilibrium, it is necessary that $\rho>r-\delta-\lambda s \bar{F}(w)$, which collapses to $\rho>r-\delta$ since it must hold at all $w \in[\underline{w}, \bar{w}]$.

The target level of assets $a^{*}(w)$ is found by equating equations (40) and (41), and the upper bound on assets is found by substituting in $w=\bar{w}$,

$$
\bar{w}+r \bar{a}=\phi\left(\frac{\delta u^{\prime}(c(\bar{a}, \underline{w}))}{\rho+\delta-r}\right) .
$$

If $\rho-r$ is small relative to $\delta$ (let $(\rho-r) / \delta \rightarrow 0$ ), this collapses to

$$
\bar{w}+r \bar{a}=c(\bar{a}, \underline{w}) .
$$

\section{C.7 Steady-State Worker Flows}

Proof of Proposition 6: Define the distribution of wages as $G(w)$, with the corresponding density $g(w)$. Additionally, define the joint distribution of assets and wages as $H(a, w)$, with the corresponding joint density as $h(a, w)$. Finally, define the measure of workers to be one, and the measure unemployed workers to be $u$.

The flow of workers from unemployment to employment is given by

$$
\mathrm{u} \bar{F}(b) \lambda \int s(x, b) h(x, b) d x,
$$

while the flow of workers from employment to unemployment is $\delta[1-\mathrm{u}]$. In steady-state, these flows must be equal, providing the equilibrium condition:

$$
\frac{\mathrm{u}}{1-\mathrm{u}}=\frac{\delta}{\lambda \int s(x, b) h(x, b) d x},
$$

where $F(b)=0$ in any equilibrium.

The flow of workers into jobs paying a wage $w$ or less is equal to $\mathrm{u} F(w) \lambda \int s(x, b) h(x, b) d x$. The flow of workers out of jobs paying wage $w$ or less comprises those whose jobs that are exogenously destroyed, $\delta G(w)[1-\mathrm{u}]$, and those who find better paying jobs,

$$
\bar{F}(w)[1-\mathrm{u}] \lambda \int_{b}^{w} \int_{\underline{a}}^{\bar{a}} s(x, y) h(x, y) d x d y .
$$


Equating the flows gives:

$$
\delta G(w)+\bar{F}(w) \lambda \int_{b}^{w} \int_{\underline{a}}^{\bar{a}} s(x, y) h(x, y) d x d y=F(w) \frac{\mathrm{u}}{1-\mathrm{u}} \lambda \int s(x, b) h(x, b) d x=\delta F(w)
$$

The relationship between the wage offer and wage acceptance distribution can be seen clearly by rewriting this as

$$
\frac{F(w)-G(w)}{\bar{F}(w)}=\frac{\lambda}{\delta} \int_{b}^{w} \int_{\underline{a}}^{\bar{a}} s(x, y) h(x, y) d x d y>0, \text { for all } w \in(\underline{w}, \bar{w}),
$$

where it is clear that the wage acceptance distribution stochastically dominates the wage offer distribution.

This relationship can be rewritten to express the wage offer distribution as a function of accepted wages, the search effort function and the joint density of assets and wages $h(a, w)$ :

$$
F(w)=\frac{\delta G(w)+\lambda \int_{b}^{w} \int_{\underline{a}}^{\bar{a}} s(x, y) h(x, y) d x d y}{\delta+\lambda \int_{b}^{w} \int_{\underline{a}}^{\bar{a}} s(x, y) h(x, y) d x d y} .
$$

The corresponding wage offer density is then:

$$
\begin{aligned}
f(w)= & \frac{\delta g(w)+\lambda \int_{\underline{a}}^{\bar{a}} s(x, w) h(x, w) d x}{\delta+\lambda \int_{b}^{w} \int_{\underline{a}}^{\bar{a}} s(x, y) h(x, y) d x d y} \\
& -\frac{\left(\delta G(w)+\lambda \int_{b}^{w} \int_{\underline{a}}^{\bar{a}} s(x, y) h(x, y) d x d y\right)\left(\lambda \int_{\underline{a}}^{\bar{a}} s(x, w) h(x, w) d x\right)}{\left(\delta+\lambda \int_{b}^{w} \int_{\underline{a}}^{\bar{a}} s(x, y) h(x, y) d x d y\right)^{2}} \\
= & \frac{\delta g(w)+\lambda \bar{F}(w) \int_{\underline{a}}^{\bar{a}} s(x, w) h(x, w) d x}{\delta+\lambda \int_{b}^{w} \int_{\underline{a}}^{\bar{a}} s(x, y) h(x, y) d x d y}
\end{aligned}
$$

\section{Notes on Solution Techniques}

\section{D.1 Value Function Approximation}

The value function is approximated using Chebyshev collocation (See Judd (1998, chs. 6, 11)):

$$
\begin{aligned}
W(a, w) & \cong \Phi(a, w) \beta, \\
W_{a}(a, w) & \cong \Phi_{a}(a, w) \beta, \\
W_{a a}(a, w) & \cong \Phi_{a a}(a, w) \beta, \\
\int_{w}^{\bar{w}} W(a, x) d F(x) & \cong \int_{w}^{\bar{w}} \Phi(a, x) \beta d F(x)=\hat{\Phi}(a, w) \beta,
\end{aligned}
$$

where $\Phi(a, w)$ is a $k_{a} k_{w} \times k_{a} k_{w}$ matrix comprising the tensor product of basis functions for $a$ and $w$ : $\Phi(a, w)=\Phi(a) \otimes \Phi(w)$. Similarly, $\Phi_{a}(a, w)=\Phi_{a}(a) \otimes \Phi(w)$ and $\Phi_{a a}(a, w)=\Phi_{a a}(a) \otimes \Phi(w)$. $\beta$ is a $k_{a} k_{w} \times 1$ vector of coefficients on the basis functions. The basis is given by the Chebyshev polynomials.

The policy functions are given by the first order conditions:

$$
\begin{aligned}
& c(a, w) \cong \phi\left(\Phi_{a}(a, w) \beta\right), \\
& s(a, w) \cong \varphi(\lambda(\hat{\Phi}(a, w)-\bar{F}(w) \Phi(a, w))),
\end{aligned}
$$


where $\phi$ and $\varphi$ are the inverse functions for the marginal utility of consumption $u^{\prime}(c)$ and the marginal cost of search effort $e^{\prime}(s)$.

Rewriting the value function from equation (31) using the polynomial approximations we have:

$$
\begin{aligned}
\rho \Phi(a, w) \beta=u(c)-e(s) & +\Phi_{a}(a, w) \beta[r a+w-c]+\frac{\sigma^{2}}{2} \Phi_{a a}(a, w) \beta \\
& +\lambda s \hat{\Phi}(a, w) \beta-\bar{F}(w) \Phi(a, w) \beta+\delta[\Phi(a, \underline{w}) \beta-\Phi(a, w) \beta] .
\end{aligned}
$$

The collocation method proceeds by solving equation (46) at the $k_{a} k_{w}$ nodes by choosing the $k_{a} k_{w}$ coefficients $\beta$.

This can be accomplished by repeatedly solving a system of linear equations as follows:

1. Use equations 44 and 45 find the policy functions for consumption and search effort, given a guess for the polynomial coefficients $\beta_{k}$,

2. Update the guess to $\beta_{k+1}$ by solving the linear system of equations specified in equation (refeq:25):

$$
\begin{aligned}
\beta_{k+1}=( & (\rho+\lambda s \bar{F}(w)+\delta) \Phi(a, w)-(r a+w-c) \Phi_{a}(a, w) \\
& \left.-\lambda s \hat{\Phi}(a, w)-\delta \Phi(a, \underline{w})-\frac{\sigma^{2}}{2} \Phi_{a a}(a, w)\right)^{-1} \times(u(c)-e(s))
\end{aligned}
$$

3. Stop if $\left\|\beta_{k+1}-\beta_{k}\right\| \leq \varepsilon_{\text {tolerance, }}$ otherwise increment $k$ and repeat.

\section{D.2 Change of Variables}

When solving the model, the following change of variables allows a much more accurate solution, even near the borrowing constraint.

Define the change of variables in assets and wages:

$$
\begin{aligned}
\mathcal{A} & =\log (a-\underline{a}+1), \\
\mathcal{W} & =\log (w+1)
\end{aligned}
$$

where the linear adjustment, $-\underline{a}+1$, ensures that $\mathcal{A}$ is bounded below by zero. Now define the new value function $\mathcal{V}$ such that:

$$
\mathcal{V}(\mathcal{A}, \mathcal{W})=W(a, w)
$$

which, along with the change of variables in assets implies:

$$
\begin{aligned}
\mathcal{V}_{\mathcal{A}}(\mathcal{A}, \mathcal{W}) \mathrm{e}^{-\mathcal{A}} & =W_{a}(a, w) \\
{\left[\mathcal{V}_{\mathcal{A A}}(\mathcal{A}, \mathcal{W})-\mathcal{V}_{\mathcal{A}}(\mathcal{A}, \mathcal{W})\right] \mathrm{e}^{-2 \mathcal{A}} } & =W_{a a}(a, w)
\end{aligned}
$$

where the second and third lines follow from

$$
\frac{d \mathcal{A}}{d a}=\frac{1}{a-\underline{a}+1}=\mathrm{e}^{-\mathcal{A}}
$$

Additionally, define the transformed wage offer distribution as:

$$
\mathcal{F}(\mathcal{W})=F\left(\mathrm{e}^{\mathcal{W}}-1\right)=F(w)
$$


We now work with the transformed value function:

$$
\begin{aligned}
\rho \mathcal{V}(\mathcal{A}, \mathcal{W})=\max _{c, s}\{u(c) & -e(s)+\mathcal{V}_{\mathcal{A}}(\mathcal{A}, \mathcal{W}) \mathrm{e}^{-\mathcal{A}}\left[r\left[\mathrm{e}^{\mathcal{A}}+\underline{a}-1\right]+\mathrm{e}^{\mathcal{W}}-1-c\right] \\
+ & \frac{\sigma^{2}}{2}\left[\mathcal{V}_{\mathcal{A} \mathcal{A}}(\mathcal{A}, \mathcal{W})-\mathcal{V}_{\mathcal{A}}(\mathcal{A}, \mathcal{W})\right] \mathrm{e}^{-2 \mathcal{A}} \\
+ & \lambda s \int \max \{\mathcal{V}(\mathcal{A}, x)-\mathcal{V}(\mathcal{A}, \mathcal{W}), 0\} d \mathcal{F}(x) \\
+ & \delta[\mathcal{V}(\mathcal{A}, \underline{\mathcal{W}})-\mathcal{V}(\mathcal{A}, \mathcal{W})]\}
\end{aligned}
$$

There are three advantages of working with this transformation. First, $\mathcal{V}(\mathcal{A}, \mathcal{W})$ has much less curvature than the original function $W(a, w)$, allowing for a lower degree polynomial approximation than the original value function. Second, we end up placing many more nodes near the borrowing constraint which is the part of the function that displays the most curvature. Third, this transformation makes the distributions of wages and assets approximately normal. This ensures that the marginal distributions have approximately the same shape as the kernel used in the nonparametric bivariate density estimation.

\section{E Summary of Notation Used}

$u(c)$ : Instantaneous utility from consumption

$e(s)$ : Instantaneous cost of search effort

$c$ : Consumption

$s$ : Search Effort

$U(a)$ : Value of being unemployed with assets $a$

$W(a, w)$ : Value of being employed with assets $a$ and wage $w$

$\phi(\cdot)$ : Inverse function of the marginal utility of consumption $u^{\prime}(c)$

$\varphi(\cdot)$ : Inverse function of the marginal cost of search $e^{\prime}(s)$

$\rho$ : Rate of time preference

$\gamma:$ Coefficient of relative risk aversion

$\zeta$ : Minimum necessary consumption level $b$ : Unemployment benefit

$w$ : Wage

$R(a)$ : Reservation wage

$a$ : Asset level

$r:$ Risk free interest rate

$\lambda:$ Arrival rate of job offers

$\delta:$ Job destruction rate

$F(w)$ : Wage offer distribution

$\bar{F}(w):[1-F(w)]$

$G(w)$ : Wage distribution

$H(a, w)$ : Joint asset and wage distribution

$\sigma^{2}$ : Variance of shock to non-labor income

$\Gamma(p)$ : Distribution of firm productivity 


\section{References}

ACEmoglu, D., And R. Shimer (1999): “Efficient Unemployment Insurance,” Journal of Political Economy, 107(5), 893-928.

AIYAGARI, S. R. (1994): "Uninsured Idiosyncratic Risk and Aggregate Saving," The Quarterly Journal of Economics, 109(3), 659-684.

Alan, S., And M. Browning (2003): "Estimating Intertemporal Allocation Parameters using Simulated Residual Estimation," CAM Working Paper 2003-03.

Alexopoulos, M., And T. Gladden (2002): "Wealth, reservation Wges, and Labor Market Transitions in the U.S.: Evidence from the Survey of Income and Program Participation," unpublished.

Algan, Y., A. Chéron, J.-O. Hairault, and F. Langot (2003): "Wealth Effect on Labor Market Transitions," Review of Economic Dynamics, 6, 156-178.

Andolfatto, D. (2002): “A Theory of Inalienable Property Rights," Journal of Political Economy, 110(2), 382-393.

Bloemen, H. G., And E. G. F. Stancanelli (2001): "Individual Wealth, Reservation Wages, and Transitions into Employment," Journal of Labor Economics, 19(2), 400-439.

Bontemps, C., J.-M. Robin, And G. VAn Den Berg (1999): “An Empirical Equilibrium Job Search Model with Search on the Job and Heterogeneous Workers and Firms," International Economic Review, 40(4), 1039-1074.

(2000): "Equilibrium Search with Continuous Productivity Dispersion: Theory and Nonparametric Estimation," International Economic Review, 41(2), 305-358.

Bowlus, A. J., N. M. Kiefer, And G. R. Neumann (1995): "Estimation of Equilibrium Wage Distributions with Heterogeneity," Journal of Applied Econometrics, 10, S119-S131.

(2001): "Equilibrium Search Models and the Transition from School to Work," International Economic Review, 42(2), 317-343.

Browning, M., T. F. Crossley, and E. Smith (2003): “Asset Accumulation and Short Term Employment," Unpublished Manuscript.

Budría Rodríguez, S., J. DÍAZ-Giménez, V. QuAdrini, and J.-V. Ríos-Rull (2002): "Updated Facts on the U.S. Distributions of Earnings, Income, and Wealth," Federal Reserve Bank of Minneapolis Quarterly Review, 26(3), 2-35.

Burdett, K. (1978): “A Theory of Employee Job Search and Quit Rates,” American Economic Review, 68(1), 212-220.

Burdett, K., And D. T. Mortensen (1998): "Wage Differentials, Employer Size, and Unemployment," International Economic Review, 39(2), 257-273. 
CARroll, C. (2004): “Theoretical Foundation of Buffer Stock Saving," NBER Working Paper No. 10867.

Castañeda, A., J. Díaz-Giménez, and J.-V. Ríos-Rull (2003): "Accounting for the U.S. Earnings and Wealth Inequality," Journal of Political Economy, 111(4), 818-57.

Christensen, B. J., R. Lentz, D. T. Mortensen, G. R. Neumann, and A. Werwatz (2005): "On the Job Search and the Wage Distribution," Journal of Labour Economics, 23(1), $31-58$.

Coles, M. (2001): "Equilibrium Wage Dispersion, Firm Size, and Growth," Review of Economic Dynamics, 4, 159-187.

Costain, J. (1999): "Unemployment Insurance with Endogenous Search Intensity and Precautionary Saving," Unpublished Manuscript.

DANFORTH, J. P. (1979): "On the Role of Consumption and Decreasing Absolute Risk Aversion in the Theory of Job Search," in Studies in the Economics of Search, ed. by S. A. Lippman, and J. J. McCall, vol. 123 of Contributions to Economic Analysis, chap. 6, pp. 109-131. NorthHolland.

DAVIDSON, R., AND J.-Y. DuClos (2000): "Statistical Inference for Stochastic Dominance and for the Measurement of Poverty and Inequality," Econometrica, 68(6), 1435-1464.

Davies, J. B., AND A. F. Shorrocks (2000): "The Distribution of Wealth," in Handbook of Income Distribution, ed. by A. B. Atkinson, and F. Bourguignon, vol. 1, chap. 11, pp. 605-675. Elsevier.

DeATON, A. (1991): "Saving and Liquidity Constraints," Econometrica, 59(5), 1221-1248.

Eckstein, Z., AND G. J. VAN Den Berg (2003): "Empirical Labor Search Models: A Survey," Forthcoming Journal of Econometrics.

GotTschalk, P., And T. M. SMeEding (1997): "Cross-National Comparisons of Earnings and Income Inequality,” Journal of Economic Literature, 35, 633-687.

Gourieroux, C., A. Monfort, and E. Renault (1993): “Indirect Inference," Journal of Applied Econometrics, 8, S85-S118.

Hall, G., AND J. Rust (2002): "Estimation Methods For Endogenously Sampled Time Series: The Case Of Commodity Price Speculation In The Steel Market," NBER technical working paper 278.

(2003): "Simulated Minimum Distance Estimation of a Model of Optimal Commodity Price Speculation with Endogenously Sampled Prices," Unpublished Manuscript.

Imai, S., And M. Keane (2004): "Intertemporal Labor Supply and Human Capital Accumulation," International Economic Review, 45(2), 601-641.

JUDD, K. L. (1998): Numerical Methods in Economics. MIT Press. 
Keane, M. P., And K. I. Wolpin (2001): "The Effect of Parental Transfers and Borrowing Constraints on Educational Attainment," International Economic Review, 42(4), 1051-1103.

Kimball, M. S. (1990): "Precautionary Savings in the Small and in the Large," Econometrica, $58,53-73$.

Krusell, P., And A. A. Smith (1998): "Income and Wealth Heterogeneity in the Macroeconomy," Journal of Political Economy, 106(5), 867-896.

Kushner, H. J. (1967): "Stochastic Stability and Control," in Mathematics in Science and Engineering, vol. 33. Academic Press, London.

LENTZ, R. (2005): “Optimal Unemployment Insurance in an Estimated Job Search Model with Savings," unpublished manuscript.

LEnTZ, R., And T. TRAnÆS (2005): "Job Search and Savings: Wealth Effects and Duration Dependence," Journal of Labor Economics, 23(3), 467-489.

MCFAdDEN, D. (1989): "A Method of Simulated Moments for Estimation of Discrete Response Models Without Numerical Integration," Econometrica: Journal of the Econometric Society, 57(5), 995-1026.

Merton, R. C. (1971): "Optimum consumption and Portfolio Rules in a Continuous-Time Model," Journal of Economic Theory, 3, 373-413.

Meyer, B. D., And J. X. Sullivan (2003): "Measuring the Well-Being of the Poor Using Income and Consumption," Journal of Human Resources, 38 Supplement, 1180-1220.

Mortensen, D. T. (1990): "Equilibrium Wage Distributions: A Synthesis," in Panel Data and Labor Market Studies, ed. by J. Hartog, G. Ridder, and J. Theeuwes, pp. 279-296. NorthHolland.

(2003): Wage Dispersion: Why are Similar Workers Paid Differently? Zeuthen lecture book series.

NeAL, D., And S. Rosen (2000): "Theories of the Distribution of Earnings," in Handbook of Income Distribution, ed. by A. B. Atkinson, and F. Bourguigon, vol. 1, chap. 7, pp. 379-427. Elsevier.

PAKES, A., AND D. POllard (1989): "Simulation and the Asymptotics of Optimization Estimators," Econometrica, 57(5), 1027-1057.

RENDÓn, S. (2006): “Job Search and Asset Accumulation Under Borrowing Constraints," International Economic Review, 47(1), 233-263.

Rogerson, R., R. Shimer, And R. Wright (2005): "Search-Theoretic Models of the Labor Market: A Survey,” Journal of Economic Literature, 43(4), 959-988.

SHIMER, R. (2006): “On-the-Job Search and Strategic Bargaining,” European Economics Review, $50,811-830$. 
Silverman, B. W. (1986): Density Esimation for Statistics and Data Analysis, Monographs on Statistics and Applied Probability. Chapman and Hall.

Sмith, A. (1993): "Estimating Nonlinear Time-Series Models Using Simulated Vector Autoregressions," Journal of Applied Econometrics, 8, S64-S84.

Toche, P. (2005): “A Tractable Model of Precautionary Saving in Continuous Time," Economics Letters, 87(2), 267-272.

WÄLDE, K. (1999): "Optimal Saving under Poisson Uncertainty," Journal of Economic Theory, 87, 194-217. 